\title{
SYNERGISMS BETWEEN METAL AND PHOTOREDOX CATALYSIS: DECONVOLUTING COMPLEX SYSTEMS
}

\author{
Alessandra A. G. Fernandes ${ }^{\mathrm{a}}$ and Igor D. Jurberga,*,(1) \\ anstituto de Química, Universidade Estadual de Campinas, 13083-862 Campinas - SP, Brasil
}

Recebido em 20/12/2019; aceito em 02/03/2020; publicado na web em 21/04/2020

\begin{abstract}
This review briefly describes the evolution of organometallic chemistry and photoredox catalysis as independent fields; followed by a more in-depth presentation and discussion of representative examples derived from their synergistic combination, which generally leads to powerful cross-coupling protocols. In this context, the rational deconvolution of these complex catalytic systems into their isolated, more simple components are evaluated in order to understand their properties and reactivities.
\end{abstract}

Keywords: photoredox catalysis; photochemistry; metal catalysis; homogeneous catalysis; organic synthesis.

\section{INTRODUCTION}

\section{Organometallic Chemistry: brief overview of the field}

The birth of organometallic chemistry can be attributed to the year of 1760, when in a military pharmacy in Paris, Cadet de Gassicourt was interested in preparing invisible inks from common ores containing cobalt, smaltite and cobaltite. However, these ores also typically contained arsenic. In the process, arsenic trioxide was generated as a by-product. The pyrolysis of this oxide, in the presence of potassium acetate produces cacodyl oxide and tetramethyldiarsine, among other products: ${ }^{1} \mathrm{As}_{2} \mathrm{O}_{3}+\mathrm{AcOK} \rightarrow\left[\left(\mathrm{AsMe}_{2}\right)_{2} \mathrm{O}\right]+\left[\mathrm{Me}_{2} \mathrm{As}-\mathrm{AsMe}_{2}\right]+\ldots$ Bunsen also worked with this mixture (which was used to be known as "Cadet's fuming arsenical liquid") and he was the responsible for providing the definitive characterization of cacodyl oxide. ${ }^{2}$

In 1827, Zeise reported for the first time the preparation of a metal $\pi$ complex $\mathrm{K}\left[\mathrm{PtCl}_{3}\left(\eta^{2}-\mathrm{C}_{2} \mathrm{H}_{4}\right)\right] \cdot \mathrm{H}_{2} \mathrm{O}$, that could be obtained from the treatment of $\mathrm{PtCl}_{2}$ with boiling $\mathrm{EtOH}$, followed by treatment with an aqueous solution of $\mathrm{KCl}^{3}$ The composition of this salt and the nature of the bond between the Pt center and the ethylene ligand was a matter of debate at the time, ${ }^{4}$ which could be solved only years later, based on the studies of Birnbaum ${ }^{5}$ and Dewar 6 Chatt and Ducanson. ${ }^{7}$ Birnbaum showed that the Zeise's salt could be directly prepared from the reaction of ethylene with $\mathrm{H}_{2} \mathrm{PtCl}_{6}$. Chatt and Ducanson explained that the surprisingly strong bond between $\mathrm{Pt}$ and the ethylene ligand can be understood as a consequence of the donation of $\pi$-electrons from the ethylene ligand to $\mathrm{Pt}$, while the back-donation from $d$ electrons of the Pt center to the ethylene $\pi^{*}$ orbital creates a linkage stronger than what could be anticipated. (This concept can be also readily applied to metal carbonyls, and with slight modifications, to aromatic complexes.)

In 1850s, Edward Frankland (a former student of Bunsen) prepared a number of air-sensitive metal-alkyl complexes, including $\mathrm{ZnEt}_{2},{ }^{8} \mathrm{HgEt}_{2}{ }^{9}, \mathrm{SnEt}_{4},{ }^{8,10}$ and $\mathrm{EtLi}^{1}{ }^{11}$ with the zinc and mercury compounds being immediately employed for the synthesis of a variety of other main-group organometallic compounds. In this context, in 1863 , Friedel and Crafts reacted $\mathrm{ZnR}_{2}$ with $\mathrm{SiCl}_{4}$ to prepare organochlorosilanes $\mathrm{R}_{\mathrm{n}} \mathrm{SiCl}_{4-\mathrm{n}} \cdot{ }^{12}$ Later, in 1868 , Schützenberger reported the first metal-carbonyl complexes $\left[\mathrm{Pt}(\mathrm{CO})_{2} \mathrm{Cl}_{2}\right]$ and $\left[\mathrm{Pt}(\mathrm{CO}) \mathrm{Cl}_{2}\right]_{2},{ }^{13}$ and in 1890 , Mond was able to isolate the first binary metal-carbonyl compound, $\mathrm{Ni}(\mathrm{CO})_{4} ;{ }^{14}$ then being followed in 1891 by the almost simultaneous reports of $\left[\mathrm{Fe}(\mathrm{CO})_{5}\right]$, by Mond ${ }^{15}$ and Berthelot. ${ }^{16}$

\footnotetext{
*e-mail: ijurberg@unicamp.br
}

Earlier, in 1828, the serendipitous preparation of urea from ammonium cyanate reported by Wöhler ${ }^{17}$ (a former student of Berzelius) attracted the attention of many chemists, thus representing a key historical event that triggered the rapid development of organic synthesis. In this context, important early examples referring to the use of metals or organometallic compounds in organic synthesis included the preparation of alkanes from alkyl halides and sodium, as reported by Wurtz in $1855,{ }^{18}$ and the $\mathrm{Cu}$-promoted dimerization of terminal alkynes, as reported by Glaser in $1869 .{ }^{19}$ At the end of the nineteenth century, in 1894, Phillips described the oxidation of ethylene to acetaldehyde, promoted by an aqueous solution containing stoichiometric amounts of a Pd salt. ${ }^{20}$ In 1899, Barbier described part of his studies using organometallic reagents of type RMX that could be formed in situ from alkyl halides RX and a metal $M(M=M g$, $\mathrm{Zn}$ ) as nucleophiles in 1,2-additions to carbonyl compounds, ${ }^{21,22}$ then being followed in 1900 by his student Victor Grignard, whose studies focused on the use of organomagnesium halides ( $\mathrm{RMgX}$ ) as strong bases and nucleophiles. ${ }^{23,24}$ The french chemist Paul Sabatier (a former student of Berthelot) was the first to differentiate homogeneous from heterogeneous catalysis. He studied the hydrogenation of olefins to alkanes in the presence of heterogeneous Nickel catalysts. ${ }^{25}$ As a consequence of these contributions, Grignard and Sabatier were awarded the Nobel Prize, approximately a decade later, in 1912.

Continuing on with the early advancements of the twentieth century, Ullman showed that $\mathrm{Cu}$ can promote the dimerization of arylbromides ${ }^{26}$ and the coupling of amines with aryl halides. ${ }^{27,28}$ In 1909, Wilhelm Ostwald was awarded the Nobel Prize for his contributions to the understanding of fundamental concepts related to catalysis, chemical equilibria and rates of reactions, which placed him as the founder of physical-chemistry. ${ }^{29}$ Ostwald had several pulpils, among them, Van't Hoff (Nobel Prize in 1901), Arrhenius (Nobel Prize in 1903), and Nernst (Nobel Prize in 1920). In 1917, Schlenk reported the first isolation of organolithium compounds (e.g. MeLi, EtLi and $\mathrm{PhLi}$ ) by reacting $\mathrm{Li}$ with the corresponding dialkyl- or diarylmercury compounds. ${ }^{30}$ Later, in 1930, Ziegler would describe the ready preparation of such compounds, by reacting $\mathrm{Li}$ with the corresponding alkyl- or aryl halides..$^{31,32}$

In 1918, Haber and Bosch were recognized with the Nobel Prize for the catalytic hydrogenation of $\mathrm{N}_{2}$ to produce $\mathrm{NH}_{3} \cdot{ }^{33}$ Since early developments, little has changed until today. A key event in the process development included the use of an $\alpha$-Fe catalyst, ${ }^{34}$ developed at BASF by Alwin Mittasch in the beginning of the $20^{\text {th }}$ century. ${ }^{35,36}$ The industrial process derived from this transformation paved the way for a revolution in the production of fertilizers. Indeed, $c a$. $80 \%$ 
of the ammonia produced in the world (>130 megatons $)^{37}$ is used in the production of fertilizers. Today, it is yet considered one of the greatest achievements of mankind in chemistry.

In 1938, as a consequence of his period in Mülheim (Ruhr area, Germany), when he was working with Franz Fischer and Hanz Tropsch, Roelen patented the first homogeneous hydroformylation reaction of olefins in the presence of synthesis gas $\left(\mathrm{CO}+\mathrm{H}_{2}\right)$ and $\mathrm{HCo}(\mathrm{CO})_{4}$ as catalyst. ${ }^{38} \mathrm{In} 1939$, Meerwein reported a Cu-mediated arylation process of electron-poor olefins with diazonium salts, ${ }^{39}$ and almost ten years later, in 1948, Reppe described the first Ni-catalyzed formal $[2+2+2]$-cycloaddition of alkynes leading to arenes. ${ }^{40,41}$ Shortly after, Pauson ${ }^{42}$ and Wilkinson ${ }^{43}$ were involved in the first reports of Ferrocene ${ }^{44}$ while Gilman reported the generation of cuprates from the reaction of alkyl lithium compounds with copper halides. ${ }^{45,46}$ In 1955, Ziegler and Natta independently described strategies to polymerize ethylene using a combination of $\mathrm{Ti}$ and $\mathrm{Al}$ complexes, ${ }^{47}$ which would years later be recognized by the Nobel Prize. ${ }^{48}$ In the following year, in 1956, Hodgkin reported the structure of vitamin $B_{12}$, the first biomolecule known at that time containing a metal-carbon bond. ${ }^{49}$ In 1959, van der Kerk reported the reduction of alkylhalides using $\mathrm{Bu}_{3} \mathrm{SnH},{ }^{50,51}$ which was then demonstrated to involve a radical chain mechanism. ${ }^{52}$ Later, this reactivity was further explored in other transformations, such as the Barton-McCombie deoxygenation ${ }^{53}$ and the Barton decarboxylation. ${ }^{54}$ Also in 1959, Smidt reported the Pd-catalyzed oxidation of olefins using $\mathrm{O}_{2}$ and $\mathrm{H}_{2} \mathrm{O}$ (Wacker oxidation); ${ }^{55,56}$ and in 1965 , Tsuji reported for the first time the use of $\mathrm{Pd}$ salts to promote the allylic alkylation of diethylmalonate. ${ }^{57}$ In $1973^{58}$ and in the following years, this strategy received several contributions from the Trost group, including numerous asymmetric catalytic protocols and elements of catalyst design. Among the contributions toward the development of Pd-catalyzed asymmetric allylic alkylation protocols (Pd-AAA), a powerful ligand, known today as the Trost ligand, would appear years later, in 1992. ${ }^{59}$

In 1966, Wilkinson described the preparation and use of $\mathrm{RhCl}\left(\mathrm{PPh}_{3}\right)_{3}$ as an efficient catalyst for hydrogenation reactions. ${ }^{60}$ In the following year, Calderon reported early examples and coined the term "olefin cross metathesis", ${ }^{61}$ then being followed by Penella in 1968, who reported that alkyne metathesis was also a feasible transformation, as it became evident from the conversion of 2-pentyne to a mixture of 2-butyne and 3-hexyne, in the presence of $\mathrm{WO}_{3}$ on silica. ${ }^{62}$ Also in 1968, Heck reported a Pd-promoted cross-coupling transformatin between olefins and organomercurials. ${ }^{63}$ This Pd-based stoichiometric version would be improved in 1971 by the contribution of Mizoroki, who described that the same olefinic product could be accessed from a Pd-catalyzed cross-coupling reaction replacing organomercurials by aryl halides. ${ }^{64}$ In 1969, Shilov reported a Ptcatalyzed transformation for a Pt-promoted oxidation of alkanes to the corresponding alcohols. ${ }^{65}$ A year later, Chauvin would accurately describe the involvement of metallocyclobutanes as key intermediates in the mechanism of olefin metathesis. ${ }^{66,67}$ After the seminal contribution of Heck and Mizoroki to the field of cross-coupling reactions, several other variants followed involving organic halides and an organometallic transmetallating species. In 1972, Corriu ${ }^{68}$ and Kumada ${ }^{69}$ reported the Ni-catalyzed cross-coupling of Grignard reagents; in 1975, Sonogashira reported on the Pd-catalyzed crosscoupling of terminal alkynes ${ }^{70}$ in $1976-77$, Negishi reported the $\mathrm{Pd}$ - or Ni-catalyzed cross-coupling of alanes or organozinc reagents with alkenyl/aryl halides ${ }^{71}$ Migita $^{72}$ and Stille ${ }^{73}$ reported on the Pdcatalyzed cross-coupling of stannanes; and in 1979, Suzuki reported the Pd-catalyzed cross-coupling of boronic acids. ${ }^{74}$ During this period, other important achievements in organometallic chemistry also included the Nobel Prize in 1973 awarded to Fischer and Wilkinson, for their contributions to the chemistry of sandwich compounds $;^{75}$ the work of Mortreux and Blanchard involving the metathesis of alkynes employing a $\mathrm{Mo}(\mathrm{CO})_{6} /$ resorcinol catalytic system $;{ }^{76}$ the work of Kagan in 1977 describing the use of $\mathrm{SmI}_{2}$ as a SET reducing agent; ${ }^{77,78}$ and the report of Crabtree in 1979 demonstrating that an Ir complex containing a cyclooctene ligand could lead to cyclooctadiene via a dehydrogenation process. ${ }^{79}$

While in 1981, Schrock reported the first well-defined catalyst for alkyne metathesis, a W(VI) alkylidyne complex; ${ }^{80}$ in 1983 , Sauvage described a new strategy to assemble interlocked molecules (catenanes) by means of Cu-based templates; ${ }^{81}$ and in 1989 , Kulinkovich reported a Ti-catalyzed preparation of cyclopropanol derivatives employing carboxylic acids. ${ }^{82}$ During this period, asymmetric synthesis was gaining momentum; and a number of new transformations have appeared, including Noyori protocol for $\mathrm{Rh}$ - or Ru-BINAP catalyzed hydrogenation of olefins; ${ }^{83}$ Narasaka $^{84}$ and Seebach $^{84}$ reports on the use of Ti-TADDOL complexes in DielsAlder cycloadditions and 1,2-additions of Grignard or organolithium reagents to aldehydes; Sharpless dihydroxylation of olefins, ${ }^{86}$ and Jacobsen ${ }^{87}$ and Katsuki ${ }^{88}$ protocols for the epoxidation of olefins.

In 1991, Arduengo reported the first stable, isolable NHC; 89 Larock introduced a convenient Pd-catalyzed indole synthesis starting from 2-iodoanilines and internal alkynes; ${ }^{90}$ and Schrock reported a highly active Mo catalyst for ring-opening alkene metathesis polymerization. ${ }^{91}$ In 1992, Shibasaki introduced the use of lanthanides-BINOL as powerful Lewis acid catalysts for a nitroaldol ${ }^{92}$ and other transformations. ${ }^{93}$ In 1993, Grubbs introduced a Ru catalyst for olefin metathesis (later called of first generation, it contained two tricyclohexylphosphine ligands). ${ }^{94}$ In 1999, a second generation Ru catalyst was developed, in which one of the phosphine ligands of the first generation catalyst had been replaced by a NHC ligand. ${ }^{95}$ Because these catalysts are not air sensitive, and generally exhibit a high functional group tolerance, they have allowed a significant extension of the scope of this transformation..${ }^{96}$ Due to the previous contributions of Schrock, Grubbs and Chauvin to the development of olefin metathesis, they were recognized with the Nobel Prize in $2005 .{ }^{97}$

In 1993, Keck also reported an asymmetric allylation method of aldehydes employing allyltributylstannane and a Ti-BINOL catalytic system; ${ }^{98}$ in 1994, Hartwig ${ }^{99}$ and Buchwald ${ }^{100}$ reported simultaneously and independently Pd-catalyzed cross-coupling strategies between aryl halides and tin amides. Later, this Pd-catalyzed C-N crosscoupling strategy was further improved to become a powerful method employed in several domains, such as in the synthesis of heterocycles, ligands and catalysts, in medicinal chemistry, in process chemistry and in chemical biology applications. ${ }^{101}$ In this context, some years later (1998), Buchwald and his group have also introduced a family of dialkylbiaryl phosphine ligands of superbe activity for Pd-catalyzed Suzuki cross-coupling reactions. ${ }^{102,103}$ Nevertheless, these ligands got increased popularity over the years for being also competent in numerous other cross-coupling transformations. ${ }^{104}$

In 1995, Jacobsen reported on the stereoselective ring-opening of epoxides, ${ }^{105}$ and Herrmann described the use of an NHC ligand in a Pd-catalyzed Heck reaction. ${ }^{106}$ In 1996, Sharpless reported an extension of his previous work, this time describing a protocol for the enantioselective catalytic aminohydroxylation of olefins. ${ }^{107}$

Approaching the $21^{\text {st }}$ century, C-H functionalization strategies received more attention. This synthetic interest can be highlighted by the reports of Periana in 1998, when his group described a Pt-based protocol to oxidize methane; ${ }^{108}$ in 2005 , Sames demonstrated a C-H functionalization process via a redox-neutral approach, consisting of Lewis acid-catalyzed 1,5-H shift/cyclization sequence for the preparation of spirocycles (Lewis acids employed: $\mathrm{Sc}(\mathrm{OTf})_{3}, \mathrm{PtCl}_{4}$, $\left.\mathrm{BF}_{3} . \mathrm{OEt}_{2}\right) ;{ }^{109,110}$ and in 2006, Bohle and Li described a $\mathrm{CuBr}$-catalyzed 
cross-dehydrogenative coupling of amines with nucleophiles, such as nitroalkanes and malonates, among others. ${ }^{111,112}$ These studies were accompanied by other impressive contributions in the following years, including: White selective oxidations using Fe(PDP) as catalyst (2007), ${ }^{113}$ Yu protocol for the Pd-catalyzed directing-group guided meta-selective functionalization of arenes (2012) ${ }^{114}$ and the highly seletive Rh-catalyzed protocols for the functionalization of linear alkanes using aryldiazoacetates, as reported by Davies (2016). ${ }^{115,116}$

Since the beginning of the $21^{\text {st }}$ century, asymmetric catalysis has been also undergoing continuous developments. The importance of the field was further brought to the spotlight by the Nobel Prize in Chemistry of 2001, when Knowles, Noyori and Sharpless were recognized for their contributions. ${ }^{117}$ In the following years, new developments included the use of a chiral counter-ion for enantioselective $\mathrm{Au}(\mathrm{I})$-catalyzed intramolecular cyclization of allenes, as reported by Toste in $2007 ; ;^{118}$ the synergistic combination of an aminocatalyst and a $\mathrm{Ru}$ photocatalyst to promote a highly stereoselective photochemical protocol for the $\alpha$-alkylation of aldehydes, as reported by MacMillan in 2008; ${ }^{119}$ TADDOL-derived phosphoramidite ligands for $\mathrm{Au}(\mathrm{I})$ asymmetric catalysis reported by Fürstner in 2010; ${ }^{120}$ the use of a NHC ligand in a heterogeneous, enantioselective Pd-catalyzed $\alpha$-arylation of ketones, as reported by Glorius in $2010 ;^{121}$ the development of chiral Cp ligands for the Rh-catalyzed enantioselective synthesis of 3,4-dihydroisoquinolin$1(2 H)$-ones, as reported by Cramer in $2012 ; 122$ the development of a pyrrolidine/pyridine bifunctional aminocatalyst/ligand for the Rh-catalyzed asymmetric $\alpha$-alkylation of ketones using ethylene, as reported by Dong in $2014 ;{ }^{123}$ and the development of chiralat-metal photoredox catalysts, as reported by Meggers, also in 2014. ${ }^{124}$ During the past years, significant achievements have been made also involving other metal-promoted transformations. Representative examples include the $\mathrm{Cu}$-catalyzed Huisguen [3+2] cycloaddition between terminal alkynes and azides, ${ }^{125}$ reported independenly and simultaneously by Meldal ${ }^{126}$ and by Fokin and Sharpless ${ }^{127}$ (this transformation became a canonical representative of click chemistry); ${ }^{128}$ the development of "Turbo Grignard" as highly reactive Grignard reagents, with practical handling and high functional group tolerance, as described by Knochel; ${ }^{129,130}$ the Pdcatalyzed reductive carbonylation of arylbromides, as described by Beller (2006), which was the first example of such a reaction to be employed in industry; ${ }^{131}$ the development of bench-stable alkyne metathesis precatalysts, as described by Fürstner; ${ }^{132} \mathrm{C}\left(\mathrm{sp}^{2}\right)-\mathrm{C}\left(\mathrm{sp}^{3}\right)$ photochemically-promoted cross-coupling reactions, promoted by the synergistic combination of a Ni-catalyst and an Ir-photoredox catalyst, as described by Molander, ${ }^{133}$ and Doyle and MacMillan; ${ }^{134}$ a Nicatalyzed carboxylation of alkyl bromides, as reported by Martin; ${ }^{135}$ a Rh-catalyzed hydrogenation of perfluorinated arenes, as reported by Glorius, ${ }^{136}$ the Ni-catalyzed decarboxylative cross-coupling reaction involving redox-active esters and alkenylzinc halides, as described by Baran, ${ }^{137}$ and the Ni-catalyzed electrochemically promoted cross-coupling of aryl halides with amines, as described by Neurock, Minteer and Baran. ${ }^{138}$ This brief presentation of selected achievements in the history of metal-promoted transformations has been chronologically ordered in Figure 1.

\section{Photoredox catalysis}

Photocatalysis can be defined as the "change in the rate of a chemical reaction or its initiation under the action of ultraviolet, visible or infrared radiation in the presence of a substance - the photocatalyst - that absorbs light and is involved in the chemical transformation of the reacting partners." 139 The ability of Nature to transform the sun energy into chemical energy has inspired chemists for more than a century. ${ }^{140}$ An example of an important photochemical transformation promoted by Nature is photosynthesis, which uses sunlight to convert carbon dioxide and water into glucose and oxygen. ${ }^{141}$ Among the wavelenghts that can be harvested from the full electromagnetic spectrum, the visible region can be considered particularly strategic in organic synthesis. The reason for this is that the UV region is associated with photons of high energy, which can be generally absorbed by organic molecules, but often implicates in unselective, or unpredictable competitive reaction pathways. The IR region is associated to photons of quite low energy and have been only rarely employed in synthesis. In contrast, although most of the organic molecules cannot absorb in the visible region, ${ }^{142,143}$ numerous metal photocatalysts and dyes can. As a consequence, general mechanisms of electron ${ }^{144}$ or energy ${ }^{145}$ transfers can be explored, thus allowing the development of new, mild and more sustainable synthetic methods.

\section{Photoredox catalysts and fundamental principles}

Most common photoredox catalysts are represented by metal complexes of $\mathrm{Ru}$ or Ir carrying polyheteroaromatic rings as ligands ${ }^{146}$ (although other metals complexes have been also reported) ${ }^{147}$ or dyes ${ }^{148}$ which are highly conjugated organic molecules also absorbing in the visible region (Figure 2).

The polyunsaturated rings present in these catalysts are chromophores that absorb the low-energy radiation associated to the visible region and promote the excitation of an electron to a higher energy orbital, thus resulting in the formation of an excited state that is both a better reducing and oxidazing agent. In the case of the metal complexes, this electronic excitation typically takes part from the metal to an electron-poor ligand ( $\mathrm{d} \pi_{\text {metal }} \rightarrow \pi^{*}$ ligand $)$, and it is called a metal to ligand charge transfer (MLCT). The singlet state of higher energy can undergo intersystem crossing (ISC) to create a triplet excited state, which has a longer lifetime, due to the spin-forbidden relaxation to the ground state. ${ }^{146}$

To a better understanding of how these electronic processes occur, the photocatalyst $\mathrm{Ru}(\mathrm{bpy})_{3}{ }^{2+}$ can be used to demonstrate these properties in greater detail. The metal species $\mathrm{Ru}^{2+}$ has 6 electrons in its $d$ orbitals $\left(\mathrm{d} \pi^{6}\right)$ and the polypyridine ligands have low-lying $\pi^{*}$ orbitals, thus becoming electron-acceptor orbitals. Upon absorption of a photon, an electron transfer has sufficient energy to occur from a $d \pi$ orbital of the metal to the $\pi^{*}$ orbital of the ligand. This electron transfer event converts $\left[\mathrm{Ru}^{\mathrm{II}}(\mathrm{bpy})_{3}\right]^{2+}$ to $\left[\mathrm{Ru}^{\mathrm{III}}(\mathrm{bpy})_{2}(\mathrm{bpy})^{\bullet \ominus}\right]^{2+}$. As a consequence, the lower energy triplet state of $*\left[\mathrm{Ru}(\mathrm{bpy})_{3}\right]^{2+}$ can act either as an oxidant or a reductant, depending on the reacting partner present in the reaction mixture ${ }^{146}$ (Scheme 1).

Electron transfer events might occur from a donor molecule (D) to the excited state of the photocatalyst via a reductive quenching cycle; or from the excited catalyst to an acceptor molecule (A), via an oxidative quenching cycle (Scheme 2 ). In the oxidative quenching cycle, the electron transfer event occurs from the $\pi^{*}$ orbital of the complex (that is singly occupied after excitation, $c f$. Scheme 1) to A, thus forming $\mathrm{Ru}(\mathrm{bpy})_{3}{ }^{3+}$; while in the reductive quenching cycle, $\mathrm{D}$ gives an electron to the orbital $\mathrm{d} \pi$ of the metal (that is singly occupied after excitation, $c f$. Scheme 1) to produce Ru(bpy) ${ }_{3}+{ }^{144,146}$ Because every oxidative or reductive quenching cycle needs a donor and an acceptor molecule to proceed, there are some important elements of design that must be present. Some protocols do contain both donor and acceptor partners directly implicated in the desired transformation. However, it is also possible to design a photoredox catalytic cycle employing one of these elements as sacrificial agents. For instance, sacrificial donors include amines, such as $\mathrm{Et}_{3} \mathrm{~N}, \mathrm{E}_{1 / 2}\left(\mathrm{Et}_{3} \mathrm{~N}^{\bullet} \oplus / \mathrm{Et}_{3} \mathrm{~N}\right)=$ $+1.15 \mathrm{~V}$; or thioethers, such as benzylmethylsulfide. $\mathrm{E}_{1 / 2}\left(\mathrm{BnSMe}^{\bullet \oplus /}\right.$ $\mathrm{BnSMe})=+1.25 \mathrm{~V}$, or other electron-rich molecules, such as anisole $\left.\mathrm{E}_{1 / 2}\left(\mathrm{PhOMe} \mathrm{e}^{\bullet} / \mathrm{PhOMe}\right)=+1.76 \mathrm{~V}\right)$. Examples of sacrificial acceptors 

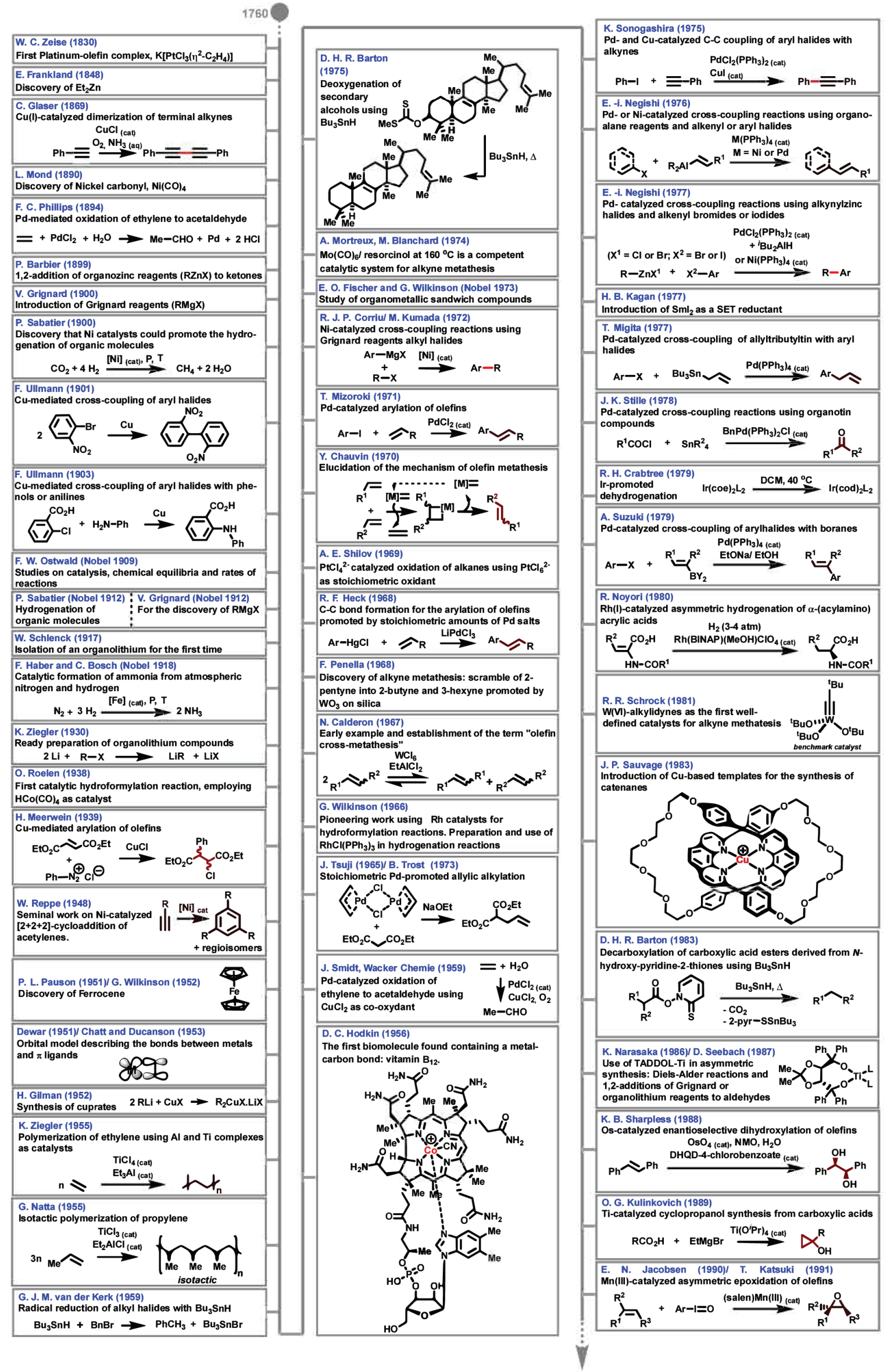

Figure 1. A selection of important achievements in organometallic chemistry since 1760 


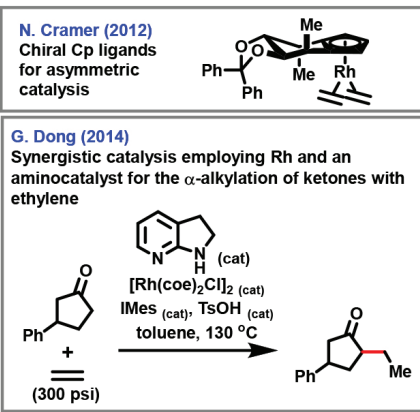

E. Meggers (2014)

Enantioselective catalysis using chiral-at-metal photoredox catalysts
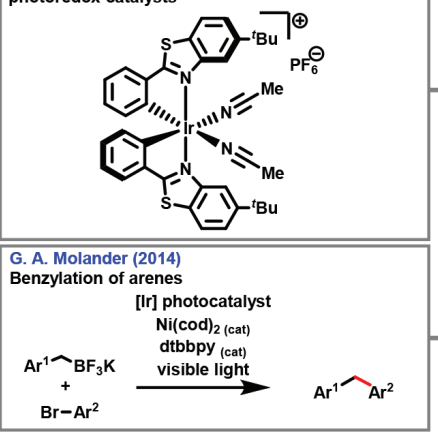

A. G. Doyle and D. W. C MacMillan (2014) Decarboxylative arylation of aminoacids

$$
\begin{aligned}
& \text { [Ir] photocatalys } \\
& { }_{-\mathrm{CO}_{2} \mathrm{H}} \mathrm{NiCl}_{2} \text {.glyme }{ }_{\text {(cat) }} \\
& \begin{array}{lll}
\mathrm{Boc}_{+} & \mathrm{dtbbpy} \text { (cat) } \\
& \text { visible light } \\
\hline
\end{array} \\
& \mathrm{X}-\mathrm{Ar} \\
& \text { visible light } \\
& \overbrace{\text { Boc }}
\end{aligned}
$$

H. M. L. Davies (2016)

Highly stereoselective Rh-catalyze

functionalization of unactivated $\mathrm{C}-\mathrm{H}$ bonds

compounds

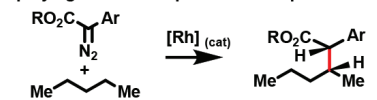

R. Martin (2017)
Ni-catalyzed carboxylation of alkyl bromides

Ni-catalyzed carboxylation of alkyl bromides
\[ \mathrm{CO}_{2}(1 \text { bar }) \]

$$
\underbrace{\mathrm{Me}}_{\mathrm{Br}} \stackrel{\substack{\mathrm{Nil}_{2} \text { (cat) } \\ \mathrm{Mn}, \mathrm{DMF}, \mathrm{Lt}}}{\longrightarrow} \underbrace{\mathrm{Me}}_{\mathrm{CO}_{2} \mathrm{He}}
$$

F. Glorius (2017)

Rh-catalyzed hydrogenation of fluorinated arenes $[\mathrm{Rh}]_{\text {(cat) }}$

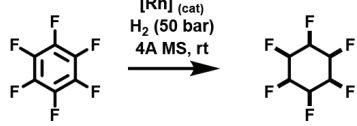

P. Baran (2017)

Redox active groups for Ni-catalyzed

(1) chlorides

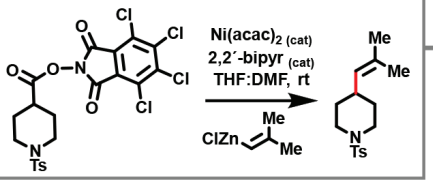

M. Neurock, S. D. Minteer and P. S. Baran (2019) Ni-catalyzed electrochemical cross-coupling of amines with aryl halides

$$
\text { ind }
$$

Future

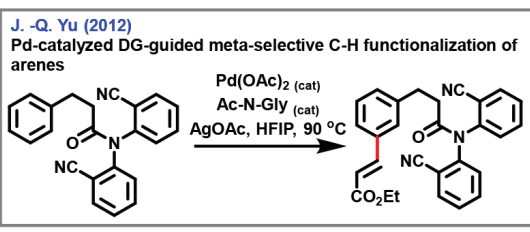

R. Heck, A. Suzuki, E.-i. Negishi (2010) Nobel Prize Award for their contributions in the development of Pd-catalyzed cross-coupling reactions

A. Fürstner (2010) Development of TADDOL-based one-point binding ligands for asymmetric gold catalysis

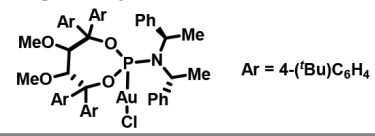

A. Fürstner (2010)
$\begin{aligned} & \text { Development of bench-stable } \\ & \text { precatalysts for alkyne metathesis }\end{aligned}$

F. Glorius (2010)

First use of NHC ligands in asymmetric heterogeneous catalysis, $\alpha$-arylation of ketone

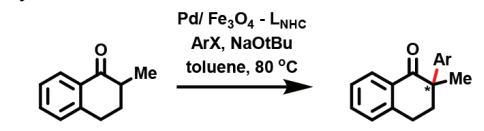

D. W. C MacMillan chiral amine (cat)

(2008)
Asymmetric $\alpha$ - $\quad \begin{gathered}\mathrm{Ru}(\text { bpy })_{3} \mathrm{Cl}_{2 \text { (cat) }} \\ \text { visible light }\end{gathered}$

alkylation of

$\stackrel{\text { visible light }}{\longrightarrow} \mathrm{H}^{\text {是 }} \mathrm{M}_{\mathrm{Me}}^{5^{5}}$ aldehydes $\mathrm{EtO}_{2} \mathrm{C} \approx \mathrm{CO}_{2} \mathrm{Et}$

M. C. White (2007)

of unactivated $\mathrm{C}-\mathrm{H}$ bonds using $\mathrm{Fe}(\mathrm{PDP})$ as catalyst
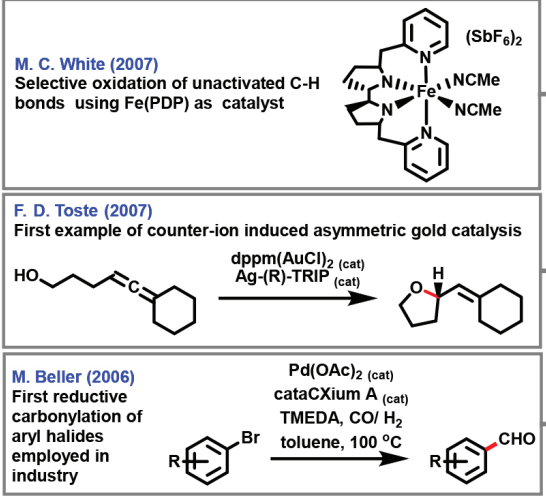

\section{S. Bohle and C.J. Li (2006)}

CuBr-catalyzed cross dehydrogenative coupling of amines with nitroalkanes
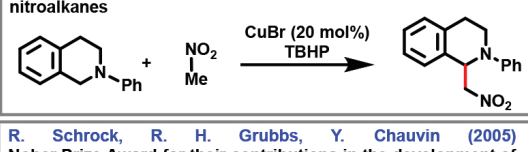
Award for their contributions in the development of olefin metathesis

\section{Sames (2005)}

LA-catalyzed catalyzed 1,5-H shift
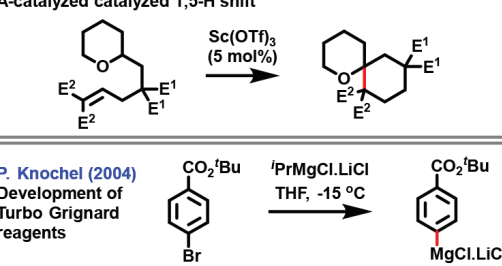

reagents M. Meldal (2002)/ V. V. Fokyn and K. B. Sharpless (2002)
Cu-catalyzed [3+2]-cycloaddition between azides and alkyne

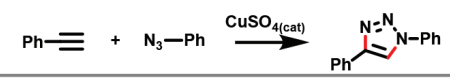

A. J. Arduengo, III (1991)

First report of a stable, isolable $\mathrm{NHC}$

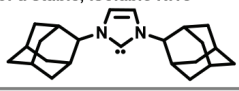

R. C. Larock (1991)

Pd-catalyzed synthesis of indoles

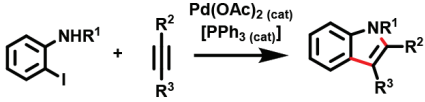

R. R. Schrock (1991)
Development of highly active
catalysts for olefin metathesis

B. Trost (1992)
Development of Trost

ligands for Pd-catalyzed

asymmetric allylic

alkylations (Pd-AAA)

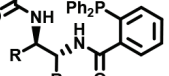

M. Shibasaki (1992)

Lewis acids made from

lathanides and BINOL

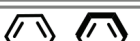

永

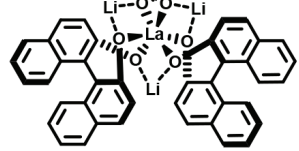

R. H. Grubbs (1993/ 1999)

Development of catalysts for olefin metathesis

displaying high funtional group tolerance

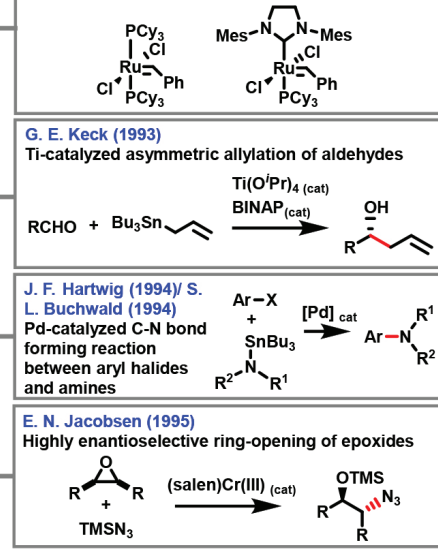

W. A. Herrmann (1995)

First use of a NHC as a ligand in a metal catalyzed transformation: a Heck reaction

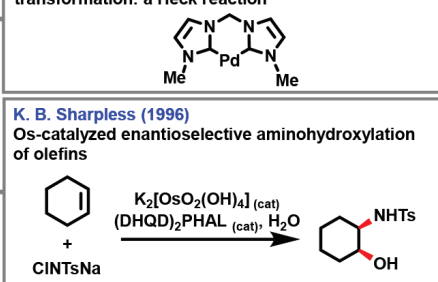

R. A. Periana (1998)

Activation of $\mathrm{CH}_{4}$ using (bpym) $\mathrm{PtCl}_{2}$

$$
\text { (cat) }
$$

S. L. Buchwald (1998)
Development of highly efficient
ligands for Pd-catalyzed cross-
coupling reactiona

W. S. Knowles, R. Noyori and K. B. Sharpless (2001) Methods for the catalytic control of stereochemistry (Hydrogenation and oxidation reactions)

Figure 1. A selection of important achievements in organometallic chemistry since 1760 (cont.) 


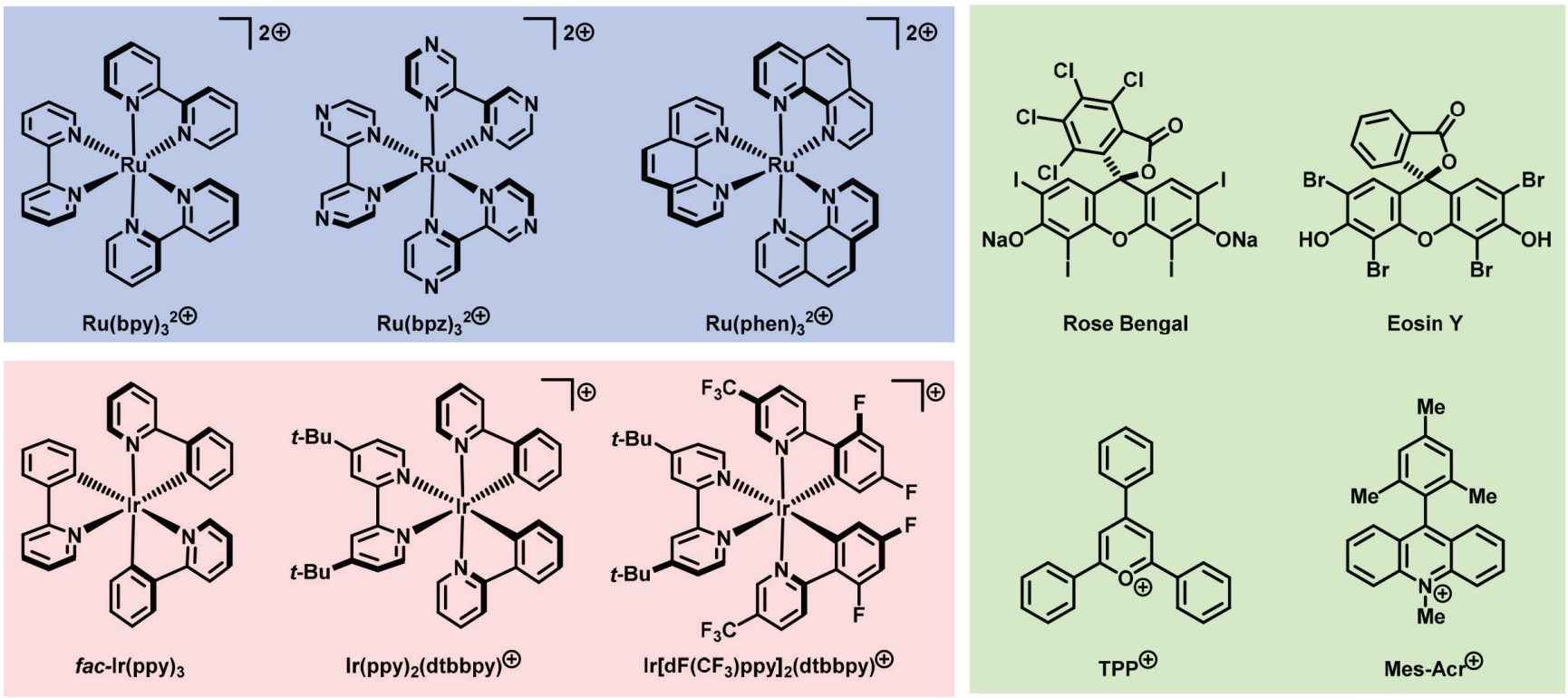

Figure 2. Examples of common photoredox catalysts (bpy =2,2'-bipyridine; bpz =2,2'-bipyrazine; phen = 1,10-phenanthroline; ppy = 2-phenylpyridine; dtbbpy $=4,4^{\prime}$-di-terc-butyl-2,2'-bipyridyne; $d F\left(C F_{3}\right)$ ppy $=2$-(2,4-difluorophenyl $)$-5-(trifluoromethyl)pyridine; $T P P=2,4,6$-triphenylpyrylium; Mes-Acr $=$ 9-mesityl-10-methylacridium)
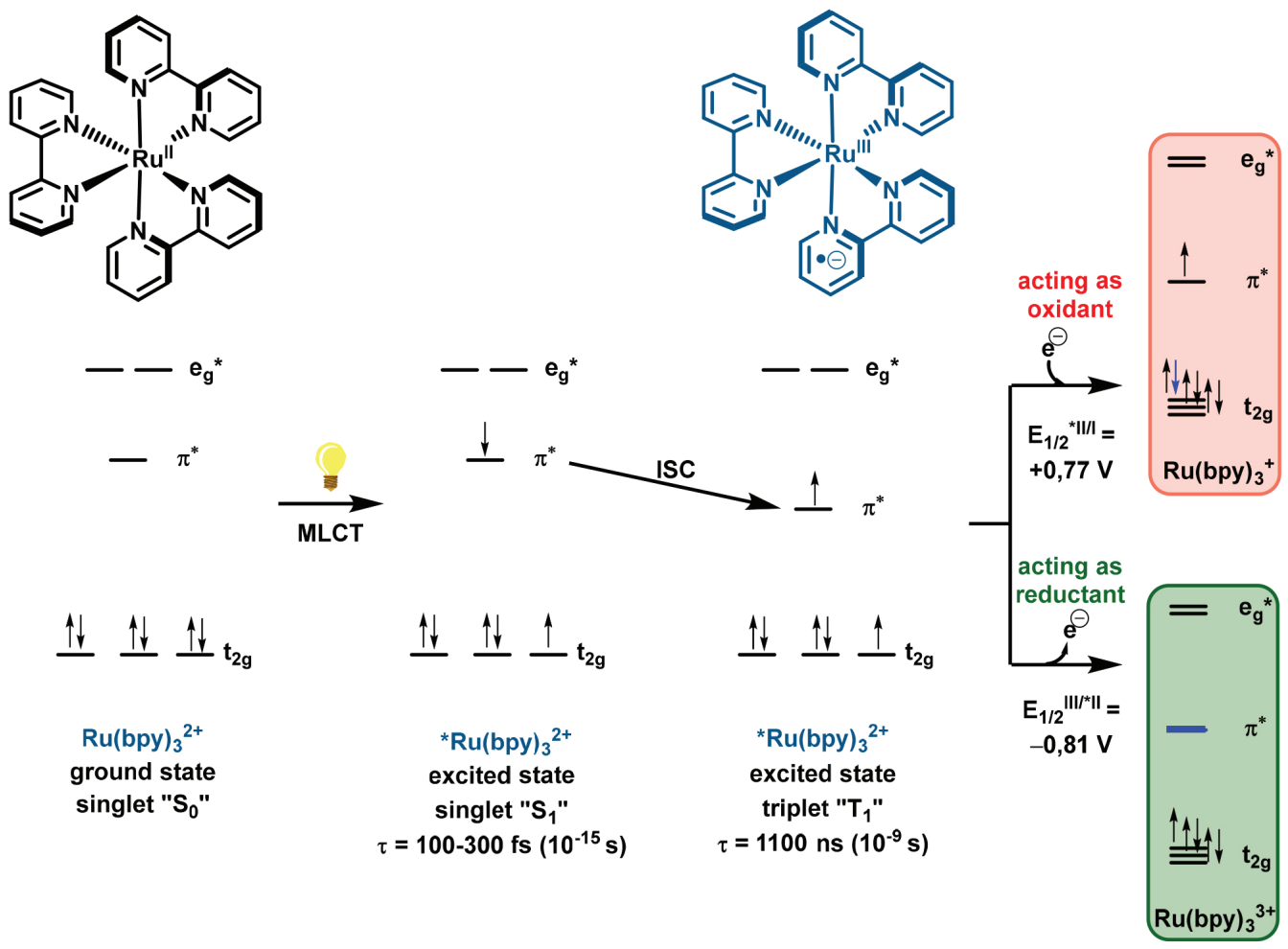

Scheme 1. Simplified molecular orbital diagram of $R u(\text { bpy })_{3}^{2+}$

include dicyanobenzenes, e.g. $\mathrm{E}_{1 / 2}\left(1,4-\mathrm{C}_{6} \mathrm{H}_{4}(\mathrm{CN})_{2} / 1,4-\mathrm{C}_{6} \mathrm{H}_{4}(\mathrm{CN})_{2}{ }^{\bullet}\right)$ $=-1.64 \mathrm{~V},{ }^{149}$ aryldiazonium salts, e.g. $\mathrm{E}_{1 / 2}\left(\mathrm{PhN}_{2} \mathrm{BF}_{4} / \mathrm{Ph} \bullet\right)=-0.16 \mathrm{~V}^{150}$ or molecular oxygen $\mathrm{E}_{1 / 2}\left(\mathrm{O}_{2} / \mathrm{O}_{2}{ }^{\ominus}\right)=-1.25 \mathrm{~V} .^{151}$

The knowledge of the redox potentials of all involved molecules in either of these catalytic cycles is important to establish whether the envisioned overall transformation is thermodynamically favored. This is a necessary condition but is not sufficient, as kinetics also play a role. Concerning thermodynamics, in the case of $\left[\mathrm{Ru}(\mathrm{bpy})_{3}\right]^{2+}$, the excited photocatalyst, having $\mathrm{E}_{1 / 2}\left(\mathrm{Ru}^{*}{ }^{* I} / \mathrm{Ru}^{\mathrm{I}}\right)=+0.77 \mathrm{~V}$, is a better oxidant than its ground state, having $\mathrm{E}_{1 / 2}\left(\mathrm{Ru}^{\mathrm{I}} / \mathrm{Ru}^{\mathrm{I}}\right)=-1.33 \mathrm{~V}$. In the same manner, its excited state $* \mathrm{Ru}(\mathrm{bpy})_{3}{ }^{2+}$ is a better reducing agent, cf. $\mathrm{E}_{1 / 2}\left(\mathrm{Ru}^{\mathrm{III}} / \mathrm{Ru}^{*} \mathrm{II}\right)=-0.81 \mathrm{~V}$ than its ground state $\left[\mathrm{Ru}(\mathrm{bpy})_{3}\right]^{2+}, c f$. $\mathrm{E}_{1 / 2}\left(\mathrm{Ru}^{\mathrm{III}} / \mathrm{Ru}^{\mathrm{II}}\right)=+1.29 \mathrm{~V}$. The redox potential and some photophysical properties of some common photocatalysts are presented in Table 1. ${ }^{146}$

The different metals and ligands employed when synthesizing photocatalysts produce distinctive redox potentials. ${ }^{146,152}$ The presence of electron donating heteroarenes typically afford more strongly reducing species, while the presence of electron withdrawing heteroarenes typically produce stronger oxidants. For instance, considering the redox potential of $\mathrm{Ru}^{\mathrm{III}} / \mathrm{Ru}^{\mathrm{II}}$, it is possible to note that when two pyrazole ligands are present, they make the oxidative power of the corresponding complex $\mathrm{Ru}(\mathrm{bpy})_{2}(\mathrm{pz})_{2}{ }^{+}$to be lower, 
cf. $\mathrm{E}_{1 / 2}\left(\mathrm{Ru}^{\mathrm{III}} / \mathrm{Ru}^{\mathrm{II}}\right)=+0.30 \mathrm{~V}$ than the one of $\mathrm{Ru}(\mathrm{bpy})_{3} \mathrm{Cl}_{2}$, cf. $\mathrm{E}_{1 / 2}\left(\mathrm{Ru}^{\mathrm{III}} / \mathrm{Ru}^{\mathrm{II}}\right)=+1.26 \mathrm{~V}$. Following the same trend, the use of strongly $\pi$-acceptor ligands, such as 2,2'-bipyrazine, makes the oxidizing power of $\mathrm{Ru}(\mathrm{bpz})_{3}{ }^{3+}$ to be even more elevated, $c f$. $\mathrm{E}_{1 / 2}\left(\mathrm{Ru}^{\mathrm{III}} / \mathrm{Ru}^{\mathrm{II}}\right)=+1.86 \mathrm{~V}$. These effects are a consequence of the reactivity of the Ru center upon MLCT events: more the Ru center is deficient in electrons, the stronger it is as an oxidizing agent. Extending this analysis to different substitutents on pyridine ligands; donor groups will destabilize the radical anion generated upon MLCT; while electronwithdrawing groups will stabilize them. Therefore, EDG on pyridine ligands will render the corresponding photocatalysts stronger reducing agents, while EWG groups will promote the opposite effect, that is, to generate weaker reducing agents $^{146,152,153}$ (Figure 3).

The energy distance $\left(\Delta_{0}\right)$ between $\mathrm{t}_{2 \mathrm{~g}}$ and $\mathrm{e}_{\mathrm{g}}$ increases with the increase of the period (of the periodic table) of the metal employed, as well as the ion charge. Therefore, $\mathrm{Ir}^{3+}$ catalysts are generally more stable than $\mathrm{Ru}^{2+}$ catalysts and can hold numerous ligands of type $\mathrm{LX}$, thus rendering more efficient charge transfers between the metal and the ligand (Figure 4). ${ }^{146}$

\section{Early examples}

An initial example in this field can be dated back to as early as 1978, when Kellogg and co-workers reported the $\mathrm{RuCl}_{2}(\mathrm{bpy})_{3}$-photomediated reduction of sulfonium ion $\mathbf{1}$, in the presence of 1,4-dihydropyridine 2 , to afford the corresponding reduced compound $\mathbf{3}$ and dimethylsulfide $\mathbf{4}^{154}$ (Scheme 3a). Then, other reports from the groups of Fukuzumi and Tanaka, ${ }^{155}$ and $\mathrm{Pac}^{156}$ described similar catalytic systems, which allowed the reduction of electron-poor olefins, aromatic ketones and benzyl halides. Some years later, in 1984, Cano-Yelo and Deronzier described the first photoredox catalyzed reaction using aryldiazonium salts as terminal oxidants for the conversion of benzyl alcohols to the corresponding aldehydes. ${ }^{157}$ They have also reported a photocatalyzed Pschorr reaction using $\mathrm{Ru}(\mathrm{bpy})_{3} \mathrm{Cl}_{2}$ for the conversion of (Z)-2-styrylbenzenediazonium salt 6 to the corresponding phenanthrene 7 in quantitative yield (Scheme $3 b) .{ }^{158}$

In 1991, Okada and co-workers demonstrated that $N$-(acyloxy) phthalimides $\mathbf{8}$ could serve as a convenient source for alkyl radicals $\mathrm{R}^{1}-\mathrm{CH}_{2} \bullet$ (Scheme $3 \mathrm{c}$ ). This radical can participate in Michael additions with electron-poor olefins leading to ketones $\mathbf{9},{ }^{159}$ chlorinated products $\mathbf{1 0},{ }^{160}$ phenylselenated compounds $\mathbf{1 1}^{161}$ or reduced compounds $\mathbf{1 2}$. $^{162,163}$

Despite these initial efforts, examples in this field remained relatively scarce until the beginning of the $21^{\text {st }}$ century. It was only in 2008, with the landmak work of Nicewicz and MacMillan, ${ }^{119}$ that catalytic photoredox transformations started to attract the attention of the synthetic organic chemistry community (Figure 5). ${ }^{164}$

Among the most important developments made so far in the field of photoredox catalysis, its merger with metal catalysis has often allowed the development of new powerful protocols, which take advantage of the best of the two worlds: allow the access to highly reactive radical intermediates, as well as generate metal intermediates that can be more easily interconverted between different oxidation states. This review aims to present the most representative developments in this intersection, while critically presenting their reactivity profiles, scope and limitations.

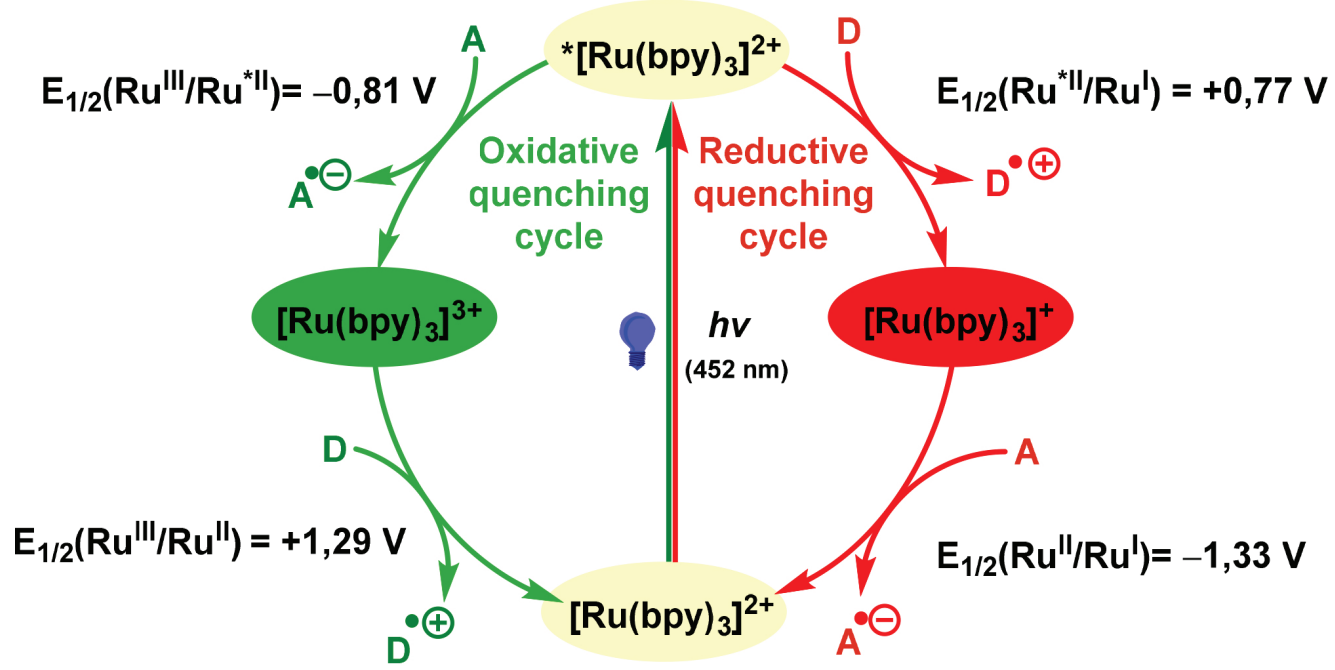

Scheme 2. Possible photoredox cycles accessible from $\left[R u(b p y)_{3}\right]^{2+}$

Table 1. Redox potentials and photophysical properties of photocatalysts in the presence of visible light ${ }^{\mathrm{a}}$

\begin{tabular}{|c|c|c|c|c|c|c|c|c|}
\hline entry & photocatalyst & $\mathrm{E}_{1 / 2}\left(\mathrm{M}^{+} / \mathrm{M}^{*}\right)$ & $\mathrm{E}_{1 / 2}\left(\mathrm{M}^{*} / \mathrm{M}^{-}\right)$ & $\mathrm{E}_{1 / 2}\left(\mathrm{M}^{+} / \mathrm{M}\right)$ & $\mathrm{E}_{1 / 2}\left(\mathrm{M} / \mathrm{M}^{-}\right)$ & $\begin{array}{l}\text { life time of the } \\
\text { excited state } \tau \\
\text { (ns) }\end{array}$ & $\begin{array}{l}\text { excitation } \lambda_{\max } \\
(\mathrm{nm})\end{array}$ & $\begin{array}{l}\text { emission } \lambda_{\max } \\
\quad(\mathrm{nm})\end{array}$ \\
\hline 1 & $\mathrm{Ru}(\mathrm{bpz})_{3}{ }^{2+}$ & -0.26 & +1.45 & +1.86 & -0.80 & 740 & 443 & 591 \\
\hline 2 & $\mathrm{Ru}(\mathrm{bpy})_{3}{ }^{2+}$ & -0.81 & +0.77 & +1.29 & -1.33 & 1100 & 452 & 615 \\
\hline 3 & $\operatorname{Ru}(\text { phen })_{3}^{2+}$ & -0.87 & +0.82 & +1.26 & -1.36 & 500 & 422 & $610^{\mathrm{b}}$ \\
\hline 4 & $\operatorname{Ir}\left[\mathrm{dF}\left(\mathrm{CF}_{3}\right) \mathrm{ppy}\right]_{2}(\mathrm{dtbbpy})^{+}$ & -0.89 & +1.21 & +1.69 & -1.37 & 2300 & 380 & 470 \\
\hline 5 & $\operatorname{Ir}(\text { ppy })_{2}(\mathrm{dtbbpy})^{+}$ & -0.96 & +0.66 & +1.21 & -1.51 & 557 & 410 & 581 \\
\hline 6 & $f a c-\operatorname{Ir}(\mathrm{ppy})_{3}$ & -1.73 & +0.31 & +0.77 & -2.19 & 1900 & 375 & $494^{c}$ \\
\hline
\end{tabular}

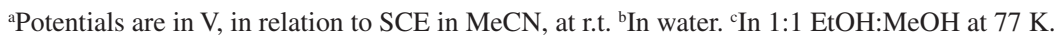




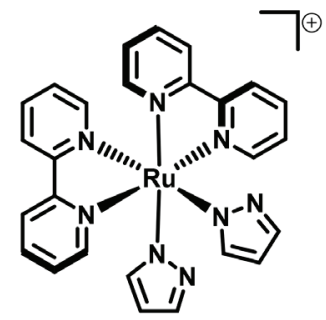

$\mathrm{Ru}(\mathrm{bpy})_{2}(\mathrm{pz})_{2}{ }^{+}$ $E_{1 / 2}\left(R u^{\prime \prime \prime} / R u^{\prime \prime}\right)=+0,30 \mathrm{~V}$

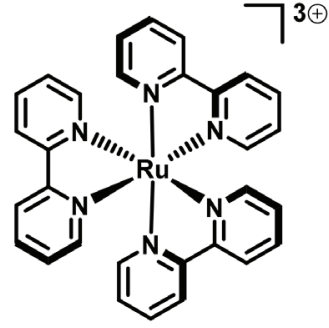

$\mathrm{Ru}(\mathrm{bpy})_{3}{ }^{3+}$ $E_{1 / 2}\left(R u^{\prime \prime \prime} / R u^{\prime \prime}\right)=+1,26 \mathrm{~V}$

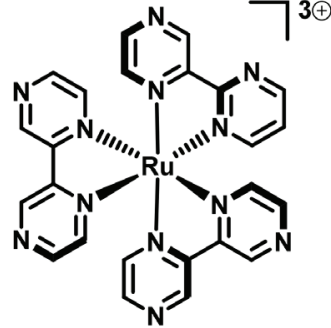

$\mathrm{Ru}(\mathrm{bpz})_{3}{ }^{3+}$ $E_{1 / 2}\left(R u^{\prime \prime \prime} / R u^{\prime \prime}\right)=+1,86 \mathrm{~V}$

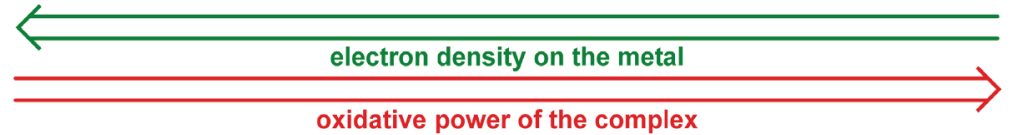

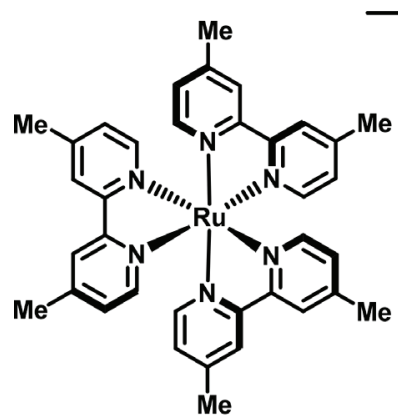

$\mathrm{Ru}(\mathrm{dmb})_{3}{ }^{+}$ $E_{1 / 2}\left(R u^{\prime \prime} / R u^{\prime}\right)=-1,45 v$

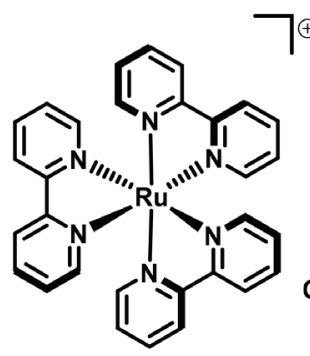

$\mathrm{Ru}(\mathrm{bpy})_{3}{ }^{+}$ $E_{1 / 2}\left(R u^{\prime \prime} / R u^{\prime}\right)=-1,35 \mathrm{~V}$

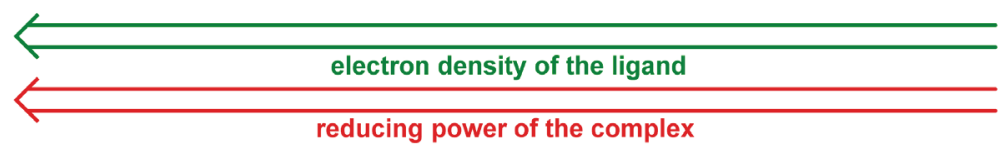

Figure 3. Effect of the ligands on the redox properties of catalyst in the ground state

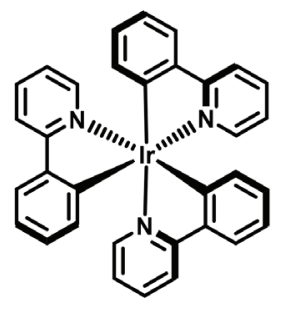

$\operatorname{Ir}(\mathrm{ppy})_{3}$ $E_{1 / 2}\left(\left|r^{*}\right| 1 / / r^{\prime \prime}\right)=+0.31 \mathrm{~V}$

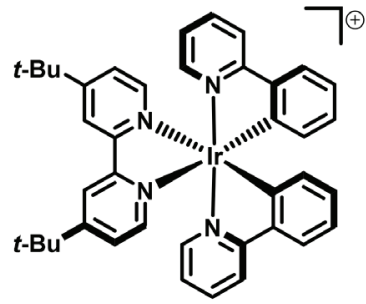

$\operatorname{Ir}(\text { ppy })_{2}(\text { dtbbpy })^{+}$ $E_{1 / 2}\left(\left|r^{*}\right| 1|/| r^{\prime \prime}\right)=+0.66 \mathrm{~V}$

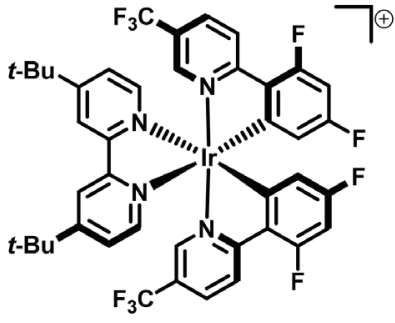

$\operatorname{Ir}\left[\mathrm{dF}\left(\mathrm{CF}_{3}\right) \mathrm{ppy}_{2} \mathrm{~d}_{2}\right.$ (dtbbpy) ${ }^{+}$

$E_{1 / 2}\left(I r^{*}|1 / /| r^{\prime \prime}\right)=+1.21 \mathrm{~V}$

oxidative power of the complex

Figure 4. Ir-based photoredox catalysts

\section{Merging photoredox catalysis and metal catalysis}

The synergistic combination of photoredox catalysis with metal catalysis has appeared as a versatile strategy for the development of new synthetic methods. The use of photoredox catalysts allows the mild generation of radical species, which in the presence of metal catalysts, can afford the coupling with non-traditional partners. Overall, photoredox catalysis can modulate oxidation states of the organometallic complexes employed, thus facilitating individual steps of a number of catalytic cycles. ${ }^{165}$

\section{Applications employing $P d$}

The combination of photoredox catalysis and metal catalysis has been accomplished for the first time in 2007, by Osawa and co-workers. ${ }^{166}$ The use of $\mathrm{Ru}(\mathrm{bpy})_{3}{ }^{2+}$ and visible light has been observed to accelerate the Sonogashira cross-coupling between aryl halides $\mathbf{1 3}$ and terminal alkynes $\mathbf{1 4}$, in the presence of $\mathrm{Pd}(\mathrm{MeCN})_{2} \mathrm{Cl}_{2}$ as catalyst, to afford the corresponding internal alkynes $\mathbf{1 5}$. The authors remarked that the excited photoredox catalyst has facilitated the oxidative addition step, but more details of the mechanism were not provided (Scheme 4).

In 2011, Sanford and co-workers have investigated the arylation of $\mathrm{C}\left(\mathrm{sp}^{2}\right)-\mathrm{H}$ of 2-arylpyridines $\mathbf{1 6}$ and aryldiazonium salts $\mathbf{1 7}$, in the presence of $\mathrm{Pd}(\mathrm{OAc})_{2}$ and $\mathrm{Ru}(\mathrm{bpy})_{3} \mathrm{Cl}_{2} \cdot 6 \mathrm{H}_{2} \mathrm{O}$ as catalysts, under blue light irradiation. ${ }^{167}$ In contrast to previous arylation protocols employing strong oxidants and/or high temperatures, ${ }^{168}$ here, the use of a photoredox catalyst allowed the same transformation in the absence of any oxidant and at rt. ${ }^{167}$ 
a) Kellogg (1978)

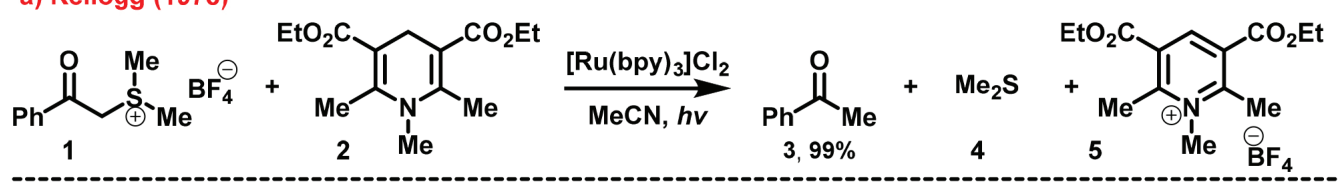

b) Cano-Yelo \& Deronzier (1984)
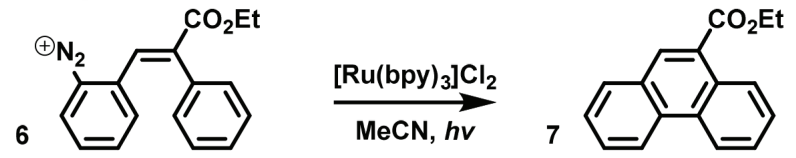

$99 \%$

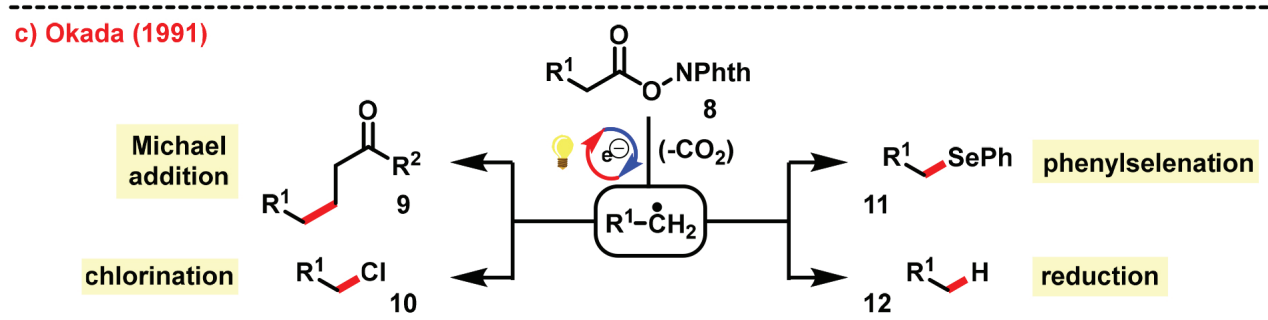

Scheme 3. Initial studies involving photoredox catalysis in organic synthesis

\section{Total Number of Publications}

\subsection{3}

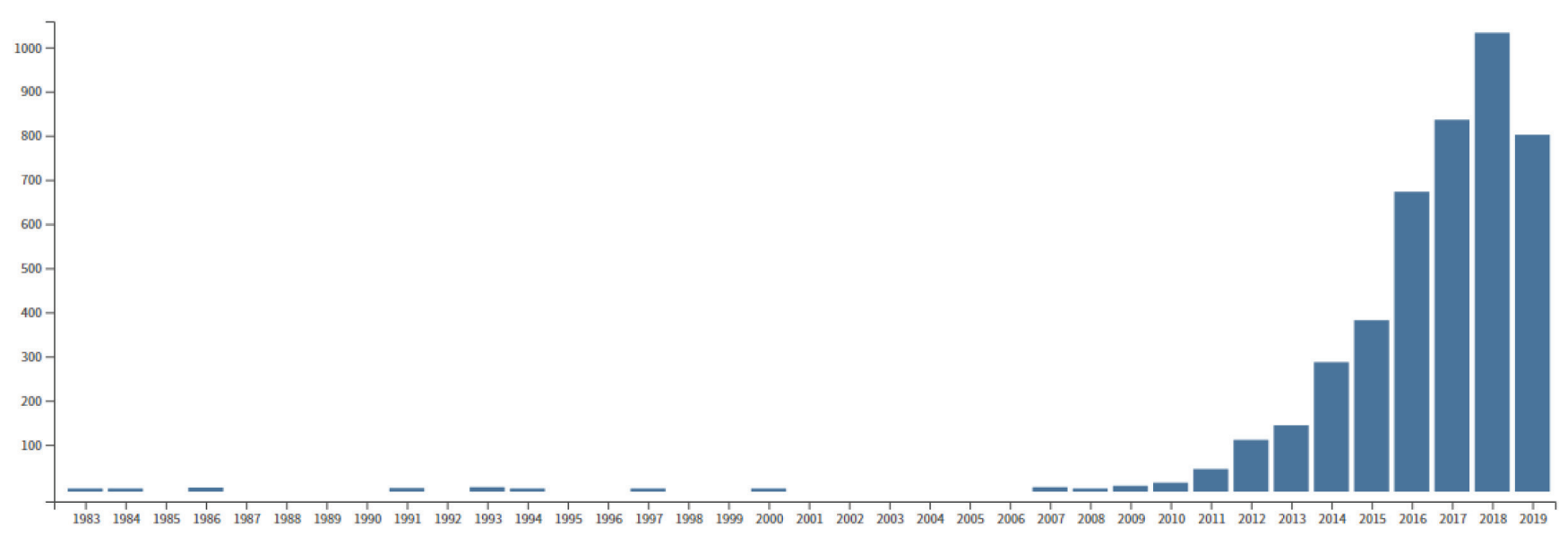

Figure 5. Recent advances observed in the number of publications on photoredox catalysis. This evolution shows the hits for the term "photoredox catalysis" 64

In the proposed mechanism, a paladacycle $\mathbf{2 0}$ is formed upon a metallation-deprotonation step involving starting substrate $\mathbf{1 6}$ and the Pd catalyst. Simultaneously, the excited photoredox catalyst * Ru reduces the aryldiazonium salt $\mathbf{1 7}$ (via a SET process) to afford the aryl radical 19. The aryl radical 19 inserts into the palladium intermediate 20 to form Pd(III) species 21. Subsequent Ru(III)-promoted oxidation of this intermediate leads to Pd(IV) 22, which then undergoes reductive elimination to produce the observed arylated products $\mathbf{1 8}$, while regenerating a Pd(II) species $^{167}$ (Scheme 5).

Years later, Rueping and co-workers reported a photoredoxcatalyzed $\mathrm{C}-\mathrm{H}$ functionalization protocol starting from aromatic enamines $\mathbf{2 3}$ in the presence of a Pd catalyst to produce indoles $\mathbf{2 4}$, while employing molecular oxygen as the terminal oxidant. ${ }^{169}$ The reported scope for this transformation included 15 examples, with yields varying from 57 to $95 \%$ (Scheme 6a).

In 2015, Wang and co-workers have demonstrated that it was possible to perform a decarboxylative $\mathrm{C}-\mathrm{H}$ acylation of phenylamides 25 using $\alpha$-ketocarboxylic acids 26 in the presence of eosin $\mathrm{Y}$ and $\mathrm{Pd}(\mathrm{OAc})_{2}$ as catalysts to afford the desired compounds 27 (Scheme 6b). ${ }^{170}$ In this same context, Tunge and co-workers reported a photoredox co-catalyzed decarboxylative Tsuji-Trost reaction converting allyl esters $\mathbf{2 8}$ to allylic compounds $\mathbf{2 9}$ (Scheme 6c). ${ }^{171}$

\section{Applications employing $\mathrm{Cu}$}

Trifluoromethylation strategies are important because the $\mathrm{CF}_{3}$ group can increase the metabolic stability of drugs, improve its permeability into membranes and favor protein-ligands interactions. ${ }^{172}$ In this context, Sanford and co-workers reported a protocol employing photoredox catalysis and $\mathrm{Cu}$ catalysis for the reaction of boronic acids 30 with $\mathrm{CF}_{3} \mathrm{I} 31$ to afford the corresponding trifluoromethyl arenes 32. ${ }^{173}$ In the proposed mechanism, the trifluoromethyl radical 33 is generated from the $\mathrm{Ru}(\mathrm{I})$-promoted reduction of $\mathrm{CF}_{3} \mathrm{I}$, followed by addition of the resulting radical 33 to the $\mathrm{Cu}(\mathrm{II}) \mathrm{X}_{2}$ complex to generate $\mathrm{Cu}$ (III) intermediate 34 . Then, this new $\mathrm{Cu}$ (III) species 34 undergoes transmetallation with the boronic acid $\mathbf{3 0}$ to afford a new $\mathrm{Cu}$ (III) species $\mathbf{3 5}$. Finally, reductive elimination of $\mathbf{3 5}$ produces the corresponding trifluoromethylated arene 32. An electron transfer between the oxidant, excited $* \mathrm{Ru}^{2+}$, and the $\mathrm{Cu}(\mathrm{I}) \mathrm{X}$ allows the turnover of both catalytic cycles (Scheme 7).

In 2015, Kobayashi and co-workers presented a photoredox 
catalyzed Cham-Lam coupling strategy between anilines $\mathbf{3 6}$ and boronic acids 30 to afford the corresponding diarylamines $37 .{ }^{174,175} \mathrm{In}$ this context, boronic acids $\mathbf{3 0}$ carrying electronwithdrawing groups could be used and the authors proposed that the role of the photoredox

Osawa (2007)

$\mathrm{Pd}(\mathrm{MeCN})_{2} \mathrm{Cl}_{2}(4 \mathrm{~mol} \%)$

$\mathrm{P}(t-\mathrm{Bu})_{3}(4 \mathrm{~mol} \%)$

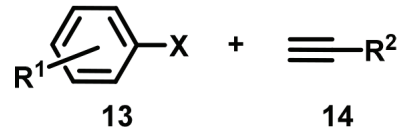

$\left[\mathrm{Ru}(\mathrm{bpy})_{3}\right]\left[\mathrm{PF}_{6}\right]_{2}(8 \mathrm{~mol} \%)$
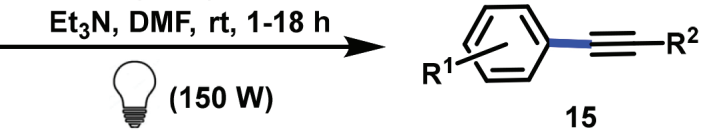

9 examples

$74-95 \%$

Scheme 4. Sonogashira cross-coupling using a Pd catalyst and a Ru photocatalyst

Sanford (2011)

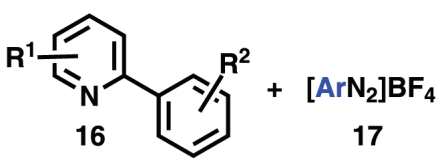

$\mathrm{Pd}(\mathrm{OAc})_{2}$ (10 $\left.\mathrm{mol} \%\right)$

$\mathrm{Ru}(\mathrm{bpy})_{3} \mathrm{Cl}_{2} .6 \mathrm{H}_{2} \mathrm{O}(2.5 \mathrm{~mol} \%)$ $\mathrm{MeOH}, \mathrm{rt}$, 5-10 h

(26 W)

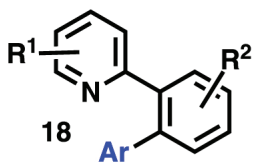

8 examples $47-76 \%$

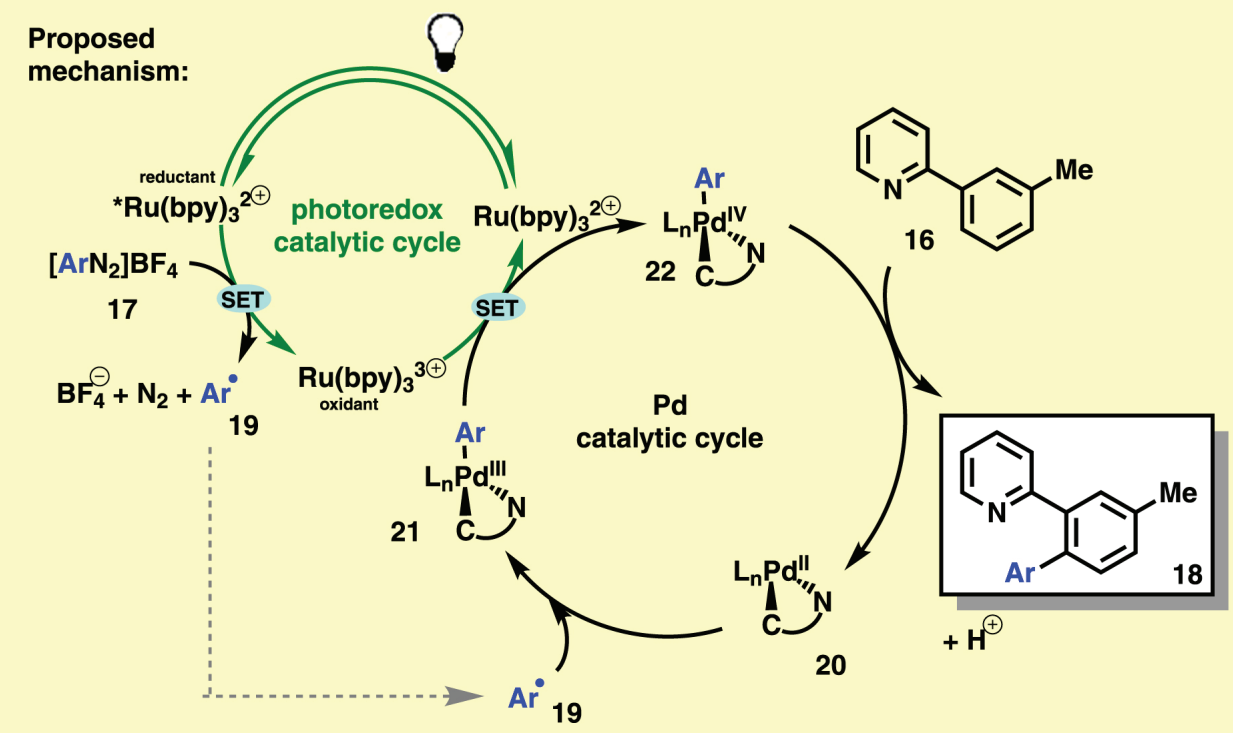

Scheme 5. Photoredox catalysis merged with $P d$-catalysis for the arylation of $C$ - $H$ bonds

a) Rueping (2014)<smiles>[R]OC(=O)C=C([R])Nc1ccc([R])cc1</smiles>

b) Wang (2015)<smiles>[R]C(=O)Nc1ccc([R2])cc1</smiles><smiles>[R]C(=O)C(=O)O</smiles>

$\mathrm{Pd}(\mathrm{OAc})_{2}$ (10 $\left.\mathrm{mol} \%\right)$

[lr(bpy)(ppy) $)_{2} \mathrm{PF}_{6}$ (3 mol\%) $\mathrm{K}_{2} \mathrm{CO}_{3}$ (3 equiv), DMF, $120^{\circ} \mathrm{C}, 24 \mathrm{~h}$ (11 W)<smiles>[R16]OC(=O)c1c([R])[nH]c2ccc([R4])cc12</smiles>

$(3 \mathrm{~W})$

c) Tunge (2014)<smiles>[R]CC(=O)OCC([R])=C</smiles>

$\mathrm{Pd}\left(\mathrm{PPh}_{3}\right)_{4}(2.5 \mathrm{~mol} \%)$

$\left[\operatorname{lr}(\mathrm{bpy})(\mathrm{ppy})_{2}\right]_{\mathrm{BF}}(0.5 \mathrm{~mol} \%)$ $\mathrm{MeCN}, 25^{\circ} \mathrm{C}, 2 \mathrm{~h}$

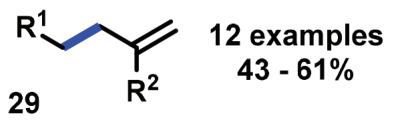



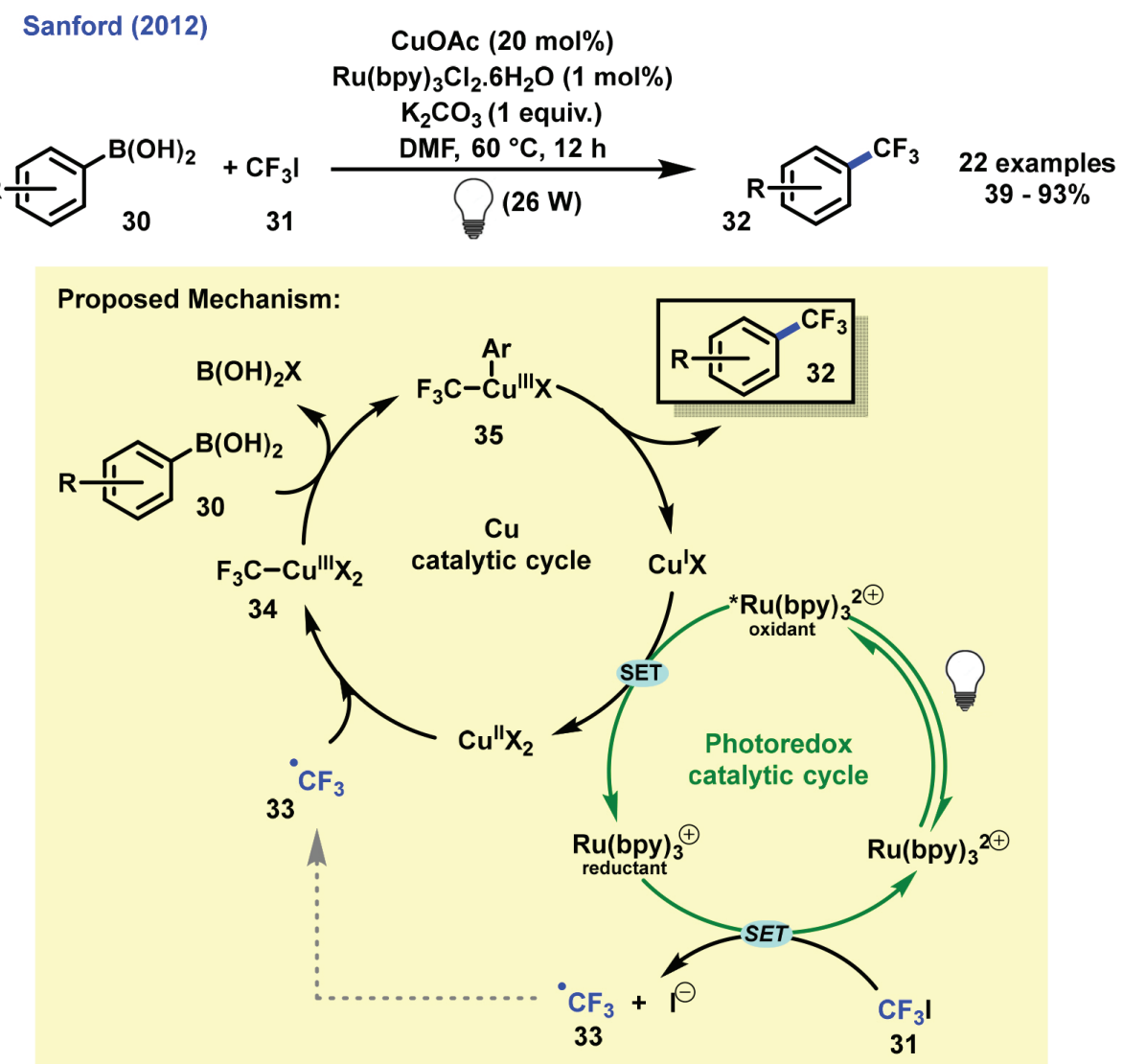

Scheme 7. An example of synergistic protocol for the trifluoromethylation of boronic acids

catalyst was to promote the efficient oxidation of $\mathrm{Cu}$ (II) to $\mathrm{Cu}$ (III) species, which could then undergo reductive elimination to produce the $\mathrm{N}-\mathrm{C}$ coupling leading to amines 37 , while also generating $\mathrm{Cu}(\mathrm{I})$ intermediates. Finally, oxidation of $\mathrm{Cu}(\mathrm{I})$ intermediates by air is proposed to regenerate the $\mathrm{Cu}$ (II) species (Scheme 8a).

Another method that uses a Cu-catalyst in the presence of a photoredox catalyst has been established by MacMillan and coworkers. ${ }^{176}$ A decarboxylative trifluoromethylation of aliphatic carboxylic acids $\mathbf{3 8}$ in the presence of Togni reagent $\mathbf{3 9}$ allowed the formation of $\mathrm{C}\left(\mathrm{sp}^{3}\right)-\mathrm{CF}_{3}$ bonds for the corresponding trifluoromethyl compounds 40. Several examples were reported, including the use of natural products and pharmaceutical drugs (Scheme 8b).

\section{Applications employing $\mathrm{Ni}$}

Metal catalysis employing $\mathrm{Ni}$ has presented solutions to some challenging cross-coupling reactions involving $\mathrm{C}\left(\mathrm{sp}^{3}\right)$. Their success is owned to the ability of promoting oxidative additions with alkyl halides, rather than undergoing $\beta$-hydride eliminations, which are fairly common to other metals, such as Pd. ${ }^{177}$

The first photoredox catalyzed transformations merged with a) Kobayashi (2015)

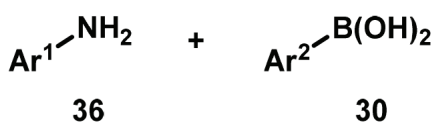

$\mathrm{Cu}(\mathrm{OAc})_{2}(10 \mathrm{~mol} \%)$

myristic acid (20 mol\%)

fac-[Ir(ppy) $)_{3}$ (1 mol\%)

\section{2,6-lutidine, 1:1 toluene:MeCN}

$35^{\circ} \mathrm{C}$, under air, $20 \mathrm{~h}$<smiles>[Al]N[Al]</smiles>

37

$42-100 \%$

b) MacMillan (2018)<smiles>O=C(O)C1CCCCC1</smiles><smiles>CC1(C)OI(C(F)(F)F)c2ccccc21</smiles><smiles>FC(F)(F)[C]1CCCCC1</smiles>

48 examples

Scheme 8. Examples of catalytic processes merging Cu-catalysis and Ir-photoredox catalysis. (BPhen = bathophenanthroline; BTMG = 2-tert-butyl-1,1,3,3-tetramethylguanididine) 
$\mathrm{Ni}$ catalysis have been reported by Molander and co-workers, ${ }^{178}$ and Doyle, MacMillan and co-workers, ${ }^{179}$ simultaneously and independently in 2014. The work of the Molander group described a $\mathrm{C}\left(\mathrm{sp}^{2}\right)-\mathrm{C}\left(\mathrm{sp}^{3}\right)$ coupling between aryl radicals generated from a SET process involving potassium organotrifluoroborates $\mathbf{4 1}$, aryl bromides 13 and an excited photoredox catalyst $* \operatorname{Ir}(\mathrm{III})$, in the presence of $\mathrm{Ni}(\mathrm{cod})_{2}$ catalyst $^{178}$ (Scheme 9).

MacMillan and Doyle reported a decarboxylative coupling between carboxylic acids, such as $\mathbf{4 3}$, and aryl halides $\mathbf{1 3}$ for the formation of the corresponding arylated amines $\mathbf{4 4}$. In the proposed mechanism, the $\operatorname{Ir}(\mathrm{III})$ photoredox catalyst is excited by visible light to generate * $\operatorname{Ir}(\mathrm{III})$, which is a good oxidant. After the deprotonation of the $\alpha$-aminoacid by the base, the oxidation of the substrate is promoted by *Ir(III) to afford an alkyl radical 45. Simultaneously, the initial catalyst $\mathrm{NiL}_{\mathrm{n}}$ undergoes oxidative addition with the aryl halide 13 to produce $\mathrm{Ni}(\mathrm{II})$-intermediate $\mathbf{4 6}$, which rapidly intercepts the alkyl radical $\mathbf{4 5}$ to form organometallic complex $\mathrm{Ni}$ (III) 47. Finally, reductive elimination from 47 generates the C-C bond of the final arylated compound $\mathbf{4 4}$ and the $\mathrm{Ni}(\mathrm{I})$ intermediate
48, which undergoes a SET promoted by the $\operatorname{Ir}(\mathrm{II})$-photocatalyst species, thus regenerating both starting catalysts, $\mathrm{NiL}_{\mathrm{n}}$ and $\operatorname{Ir}(\mathrm{III})^{179}$ (Scheme 10).

In 2016, MacMillan, Fu and co-workers reported an efficient method for the decarboxylative enantioselective arylation of aminoacids employing aryl halides, by means of photoredox catalysis merged with $\mathrm{Ni}$-catalysis. The corresponding arylated amines have been obtained in good yields and $>82 \%$ ee. ${ }^{181}$ In addition, extension of this work to the use of vinyl halides, ${ }^{181}$ and alkyl halides was also demonstrated (Scheme 11). ${ }^{182}$

In the same context, MacMillan and co-workers have also described asynergistic combination of $\operatorname{Ir}(\mathrm{III}) / \mathrm{Ni}(0)$ catalysts, acting in the presence of $\left(\mathrm{Me}_{3} \mathrm{Si}\right)_{3} \mathrm{SiH}$ (TTMSS), for the $\mathrm{C}\left(\mathrm{sp}^{2}\right)-\mathrm{C}\left(\mathrm{sp}^{3}\right)$ coupling between aryl halides $\mathbf{1 3}$ and alkyl bromides $\mathbf{5 6}$ to produce the corresponding arylated compounds 57. ${ }^{183}$ The mechanism of this transformation is believed to proceed via the generation of bromine radical $\mathbf{5 8}$ from a SET between the excited photocatalyst * $\operatorname{Ir}(\mathrm{III})$ and a bromide anion, followed by hydrogen abstration from $\left(\mathrm{Me}_{3} \mathrm{Si}\right)_{3} \mathrm{SiH}$ to produce the corresponding silicon radical 59. Then,

$\operatorname{Ir}\left[\mathrm{dFCF}_{3} \mathrm{ppy}_{2}(\mathrm{bpy}) \mathrm{PF}_{6}(2 \mathrm{~mol} \%)\right.$

$\mathrm{Ni}(\mathrm{cod})_{2}(3 \mathrm{~mol} \%)$

dtbbpy (3 $\mathrm{mol} \%)$

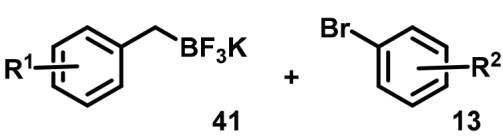

2,6-lutidine (3.5 equiv.)

95:5 acetone:MeOH, $24 \mathrm{~h}$

$(26 \mathrm{~W})$

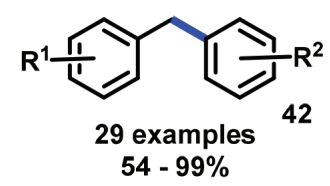

Scheme 9. Combination of $\operatorname{Ir}(\mathrm{III}) / \mathrm{Ni}(\mathrm{O})$ catalysts for the Csp ${ }^{2}-\mathrm{Csp}^{3}$ coupling between aryl bromides and potassium organotrifluoroborates $($ cod $=1,5$-cyclooctadieene)

MacMillan e Doyle (2014)
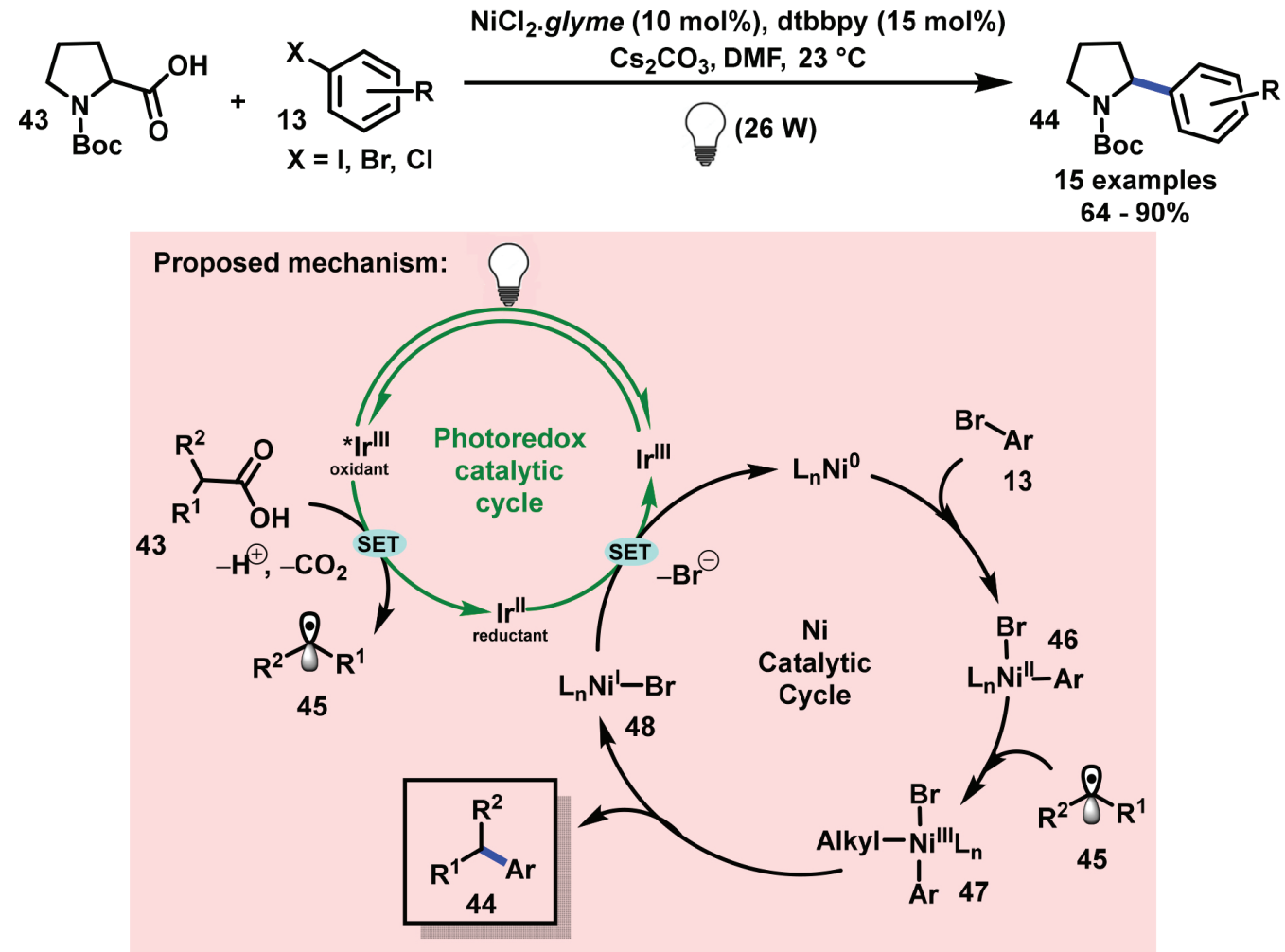

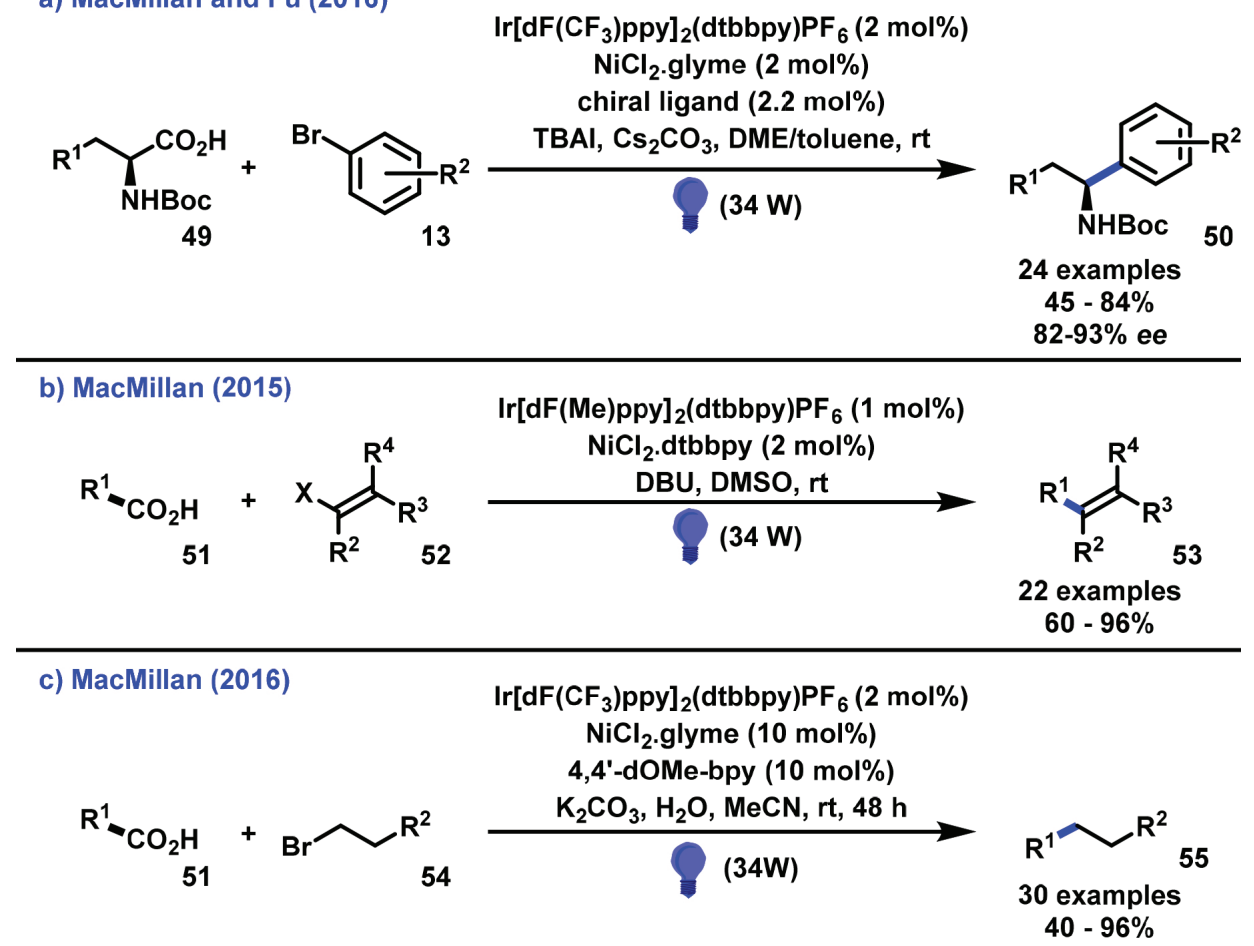

Scheme 11. Decarboxylative protocols employing Ni-catalysis and Ir-photoredox catalysis (TBAI = tetrabutylammonium iodide; DME = 1,2-dimethoxyethane; $d F(M e) p p y=2-(2,4)$-difluorophenyl-5-methylpyridine; $D B U=1,8$-diazabicyclo[5.4.0]undec-7-ene; 4,4'-dOMe-bpy = 4,4'-dimethoxy-2,2'-bipyridine)

the silicon radical 59 reacts with the alkyl bromide $\mathbf{5 6}$ to generate an alkyl radical 60, which adds to the $\mathrm{Ni}$ (II) species $\mathbf{6 1}$ (derived from the oxidative addition of aryl bromide $\mathbf{1 3}$ and $\left.\mathrm{Ni}(0) \mathrm{L}_{\mathrm{n}}\right)$ to afford the $\mathrm{Ni}(\mathrm{III})$ intermediate 62. Finally, reductive elimination leads to $\mathrm{Ni}(\mathrm{I})$ species 63, which undergoes a single electron reduction from Ir(II)photocatalyst to simultaneously regenerate $\mathrm{Ir}(\mathrm{III})$ and $\mathrm{Ni}(0)$ catalysts, as discussed in some of the previous protocols (Scheme 12).

In 2017, another protocol reported by the MacMillan group involved the combination of three types of catalysis: metallic, photoredox and organocatalyis. Using this approach, aldehydes 64 could be arylated with aryl halides $\mathbf{1 3}$ to the corresponding ketones 65 (Scheme 13) ${ }^{184}$ Because the excited complex * $\operatorname{Ir}(\mathrm{III})$ is a strong oxidant, $\mathrm{E}_{1 / 2}\left(\mathrm{Ir} * \mathrm{III} / \mathrm{Ir}^{\mathrm{II}}\right)=+1.21 \mathrm{~V}$, it can remove one electron from quinuclidine to generate the corresponding radical cation 66. In the presence of the aldehyde $\mathbf{6 4}$, the radical cation of quinuclidine 66 abstracts a hydrogen atom to form the corresponding acyl radical 67. Upon oxidative addition of the catalyst $\mathrm{NiBr}_{2}$ with aryl halide $\mathbf{1 3}$, which produces intermediate $\mathbf{6 9}$, it undergoes addition of the radical 67 to generate the $\mathrm{Ni}(\mathrm{III})$ species $\mathbf{7 0}$. Then, reductive elimination and single electron reduction of the resulting $\mathrm{Ni}(\mathrm{I})$ catalyst $\mathbf{7 1}$ produces the observed ketones $\mathbf{6 5}$ and regenerates both catalytic species $\mathrm{Ni}(0)$ and Ir(III). This reactivity has been demonstrated for several aryl bromides and some vinyl and alkyl bromides. In this context, aromatic, linear, branched and cyclic aldehydes can be also employed (Scheme 13).

Coupling reactions involving $\mathrm{C}-\mathrm{X}(\mathrm{X}=$ heteroatom) have been also investigated by means of the merger of $\mathrm{Ni}$ catalysis with photoredox catalysis. The formation of $\mathrm{C}-\mathrm{N}$ bonds has been reported by the groups of Jamison, ${ }^{185}$ Oderinde and Johannes, ${ }^{186}$ Buchwald and MacMillan ${ }^{187}$ and Molander ${ }^{188}$ (Scheme 14). The work of Jamison involves the conversion of iodoacetanilides $\mathbf{7 2}$ and alkenes $\mathbf{7 3}$ to indolines 74. Stoichiometric studies and cyclic voltammetry of the $\mathrm{Ni}$ complexes indicate that the oxidation of $\mathrm{Ni}(\mathrm{II})$ to $\mathrm{Ni}$ (III), which is promoted by the photoredox catalyst, is necessary for the C-N coupling, thus avoiding the formation of Heck-type products via a competitive $\beta$-elimination event ${ }^{185}$ (Scheme 14a).
In 2016, Oderinde, Johannes and co-workers reported the formation of $\mathrm{C}-\mathrm{N}$ bonds by the coupling of anilines $\mathbf{3 6}$ with aryl iodides $\mathbf{1 3}$ to afford diarylamines $\mathbf{3 7}$. The $\operatorname{Ir}(\mathrm{III})$ photoredox catalyst is responsible for oxidizing the employed amine, and then to reduce the $\mathrm{Ni}$ (II) catalyst to $\mathrm{Ni}(\mathrm{I})$. This methodology is efficient and can tolerate several functional groups, such as alcohols, fluorides, chlorides, aldehydes, ketones, carbamates, eters, cyanides, ethers, thioethers, alkynes, among others ${ }^{186}$ (Scheme 14b).

The formation of a $\mathrm{C}-\mathrm{N}$ bond has been also described by Buchwald and MacMillan for the preparation of heteroaromatic amines 77 starting from aryl bromides 75 and amines 76 in the presence of a $\mathrm{Ni}(\mathrm{II})$ catalyst and an $\mathrm{Ir}(\mathrm{III})$ photoredox catalyst. In collaboration with Merck, the coupling between 18 drug candidates containing halides and piperidine derivatives has been tested. Among these tests, most of them $(78 \%)$ presented the coupled product, therefore demonstrating the power of this strategy ${ }^{187}$ (Scheme 14c).

Recently, Molander reported a strategy of aminomethylation employing arylbromides $\mathbf{7 5}$ and a silylmethylamines $\mathbf{7 8}$ to produce the corresponding products $\mathbf{7 9}$ via a synergistic combination of $\mathrm{Ni}$ catalysis/photoredox catalysis. The relatively low redox potential of silylated methylamines allows the formation of $\alpha$-amino radicals that can be engaged in cross-coupling transformations with numerous aryl halides $^{188}$ (Scheme 14d).

In 2015, MacMillan and co-workers reported the coupling between alcohols $\mathbf{8 0}$ and aryl bromides $\mathbf{1 3}$ for the formation of C-O bonds in ethers 81 . The * $\operatorname{Ir}(\mathrm{III})$ species oxidizes the $\mathrm{Ni}$ (II) catalyst $\mathbf{8 3}$ to $\mathrm{Ni}$ (III) intermediate $\mathbf{8 4}$. Then, reductive elimination leads to the $\mathrm{Ni}(\mathrm{I})$ species $\mathbf{8 5}$, while generating cross-coupled product $\mathbf{8 1}$. Then, intermediate $\mathbf{8 5}$ is reduced by an $\operatorname{Ir}(\mathrm{II})$ species to to afford $\mathrm{L}_{\mathrm{n}} \mathrm{Ni}(0)$, thus turning over both catalytic cycles ${ }^{189}$ (Scheme 15).

Aiming at the formation of C-S bonds, Oderinde, Johannes and co-workers reported in 2016 a thioetherification of aryl iodides $\mathbf{1 3}$ involving a sulfur radical formed from the oxidation of thiols 86 using an $\operatorname{Ir}(\mathrm{III})$ photoredox catalyst. The generated $\mathrm{Ir}(\mathrm{II})$ reduced the $\mathrm{Ni}(\mathrm{II})$ 


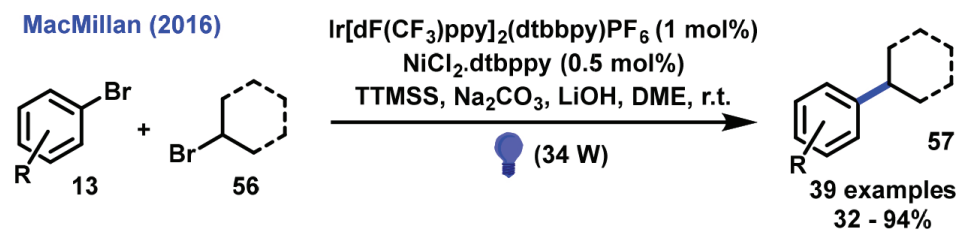

Proposed mechanism:

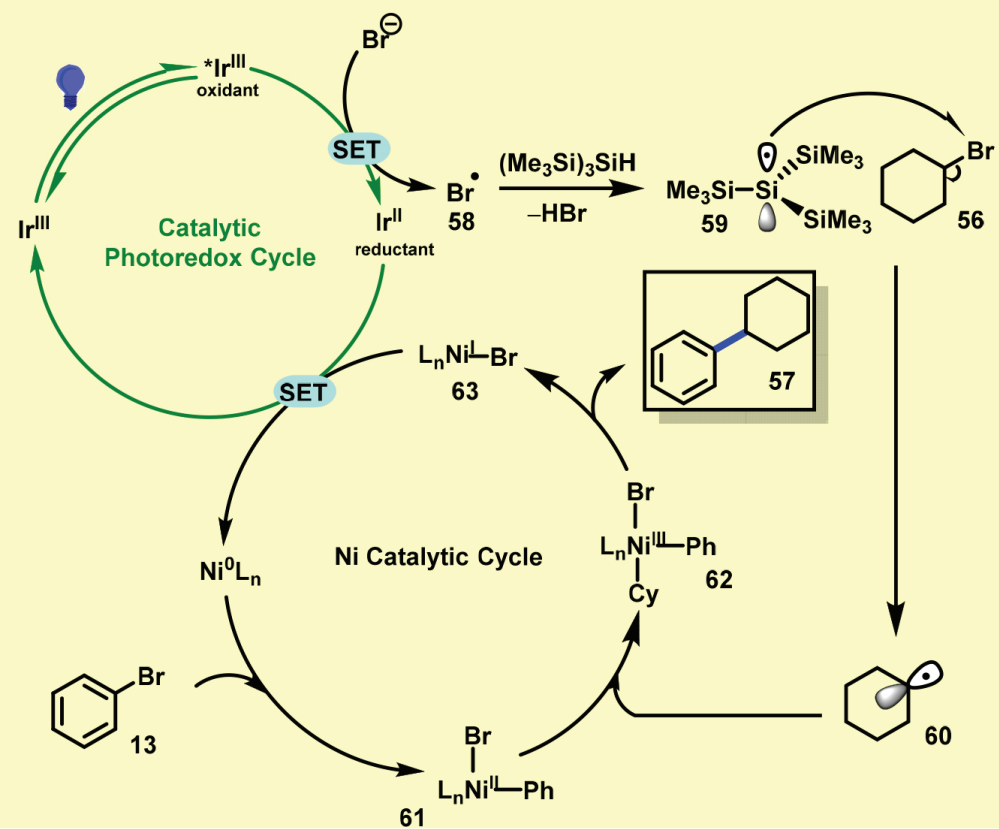

Scheme 12. Synergistic combination of $\operatorname{Ir}(I I I) / N i(0)$ catalysts for the $C\left(s p^{2}\right)$-C $\left(s p^{3}\right)$ coupling between aryl bromides and alkyl bromides $(D M E=1,2$-dimethoxyethane)
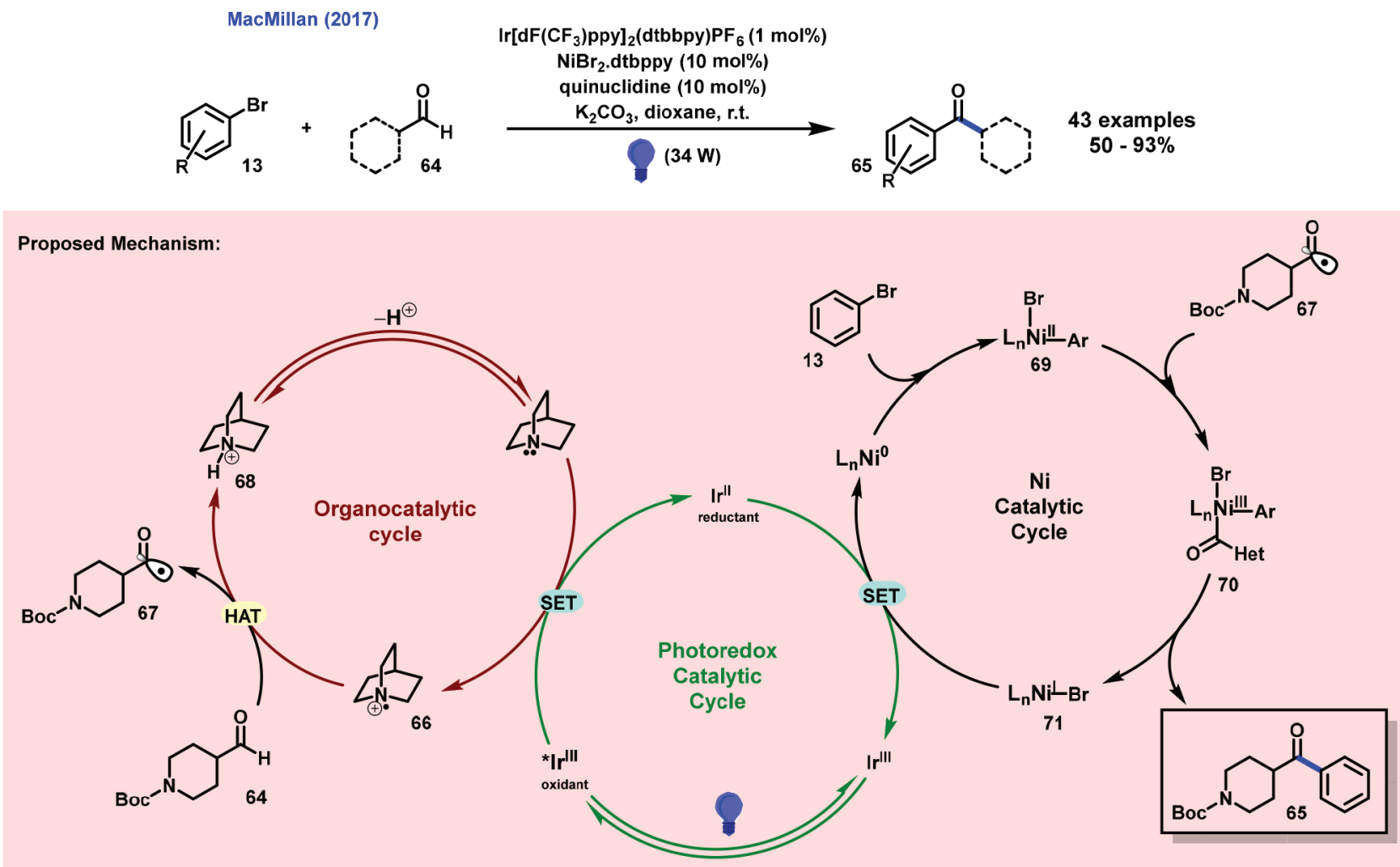

Scheme 13. C-H bond arylation of aldehydes via Ni catalysis, photoredox and organocatalysis 
a) Jamison (2015)

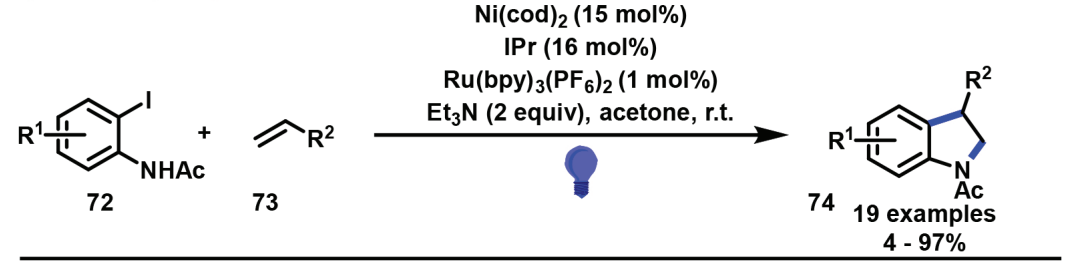

b) Oderinde and Johannes (2016)

$\mathrm{NiCl}_{2}$.dtbbpy $(10 \mathrm{~mol} \%)$

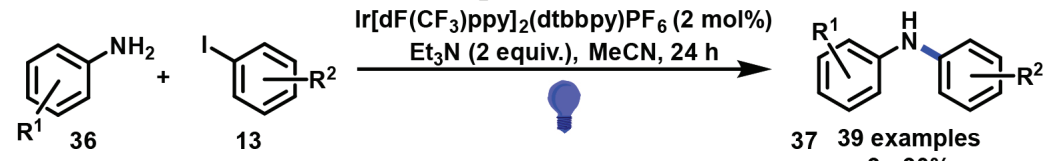

$9-90 \%$

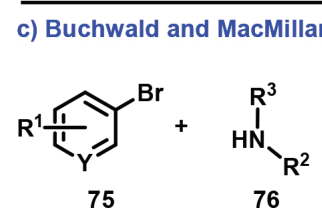

$\mathrm{NiX}_{2}$.glyme $(5 \mathrm{~mol} \%)$

$\operatorname{Ir}\left[\mathrm{dF}\left(\mathrm{CF}_{3}\right) \mathrm{ppy}_{2}(\mathrm{dtbbpy}) \mathrm{PF}_{6}(0.02 \mathrm{~mol} \%)\right.$

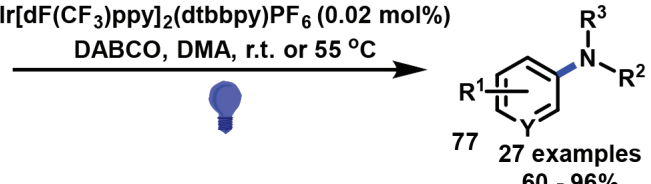

d) Molander (2017)

$60-96 \%$

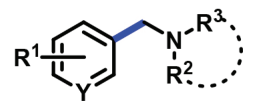

7925 examples

$41-83 \%$

Scheme 14. Representative examples of protocols merging Ni catalysis and photoredox catalysis aiming at the preparation of more elaborated amines $($ IPr $=$ 1,3-Bis(2,6-diisopropylphenyl)-1,3-dihydro-2H-imidazol-2-ylidene; DABCO =1,4-diazabicyclo[2.2.2]octane; DMA = N,N-dimethylacetamide)
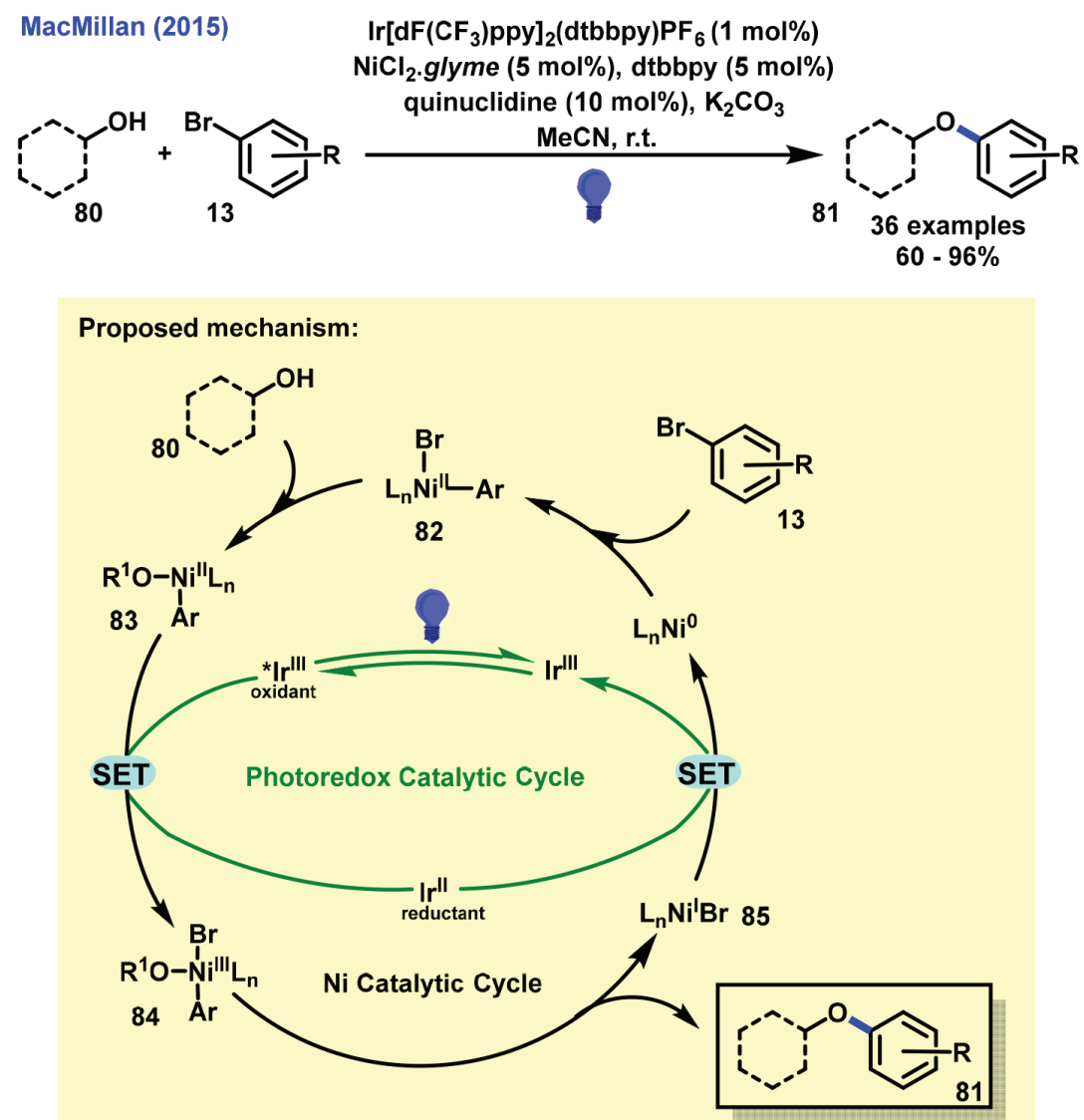
a) Oderinde and Johannes (2016)
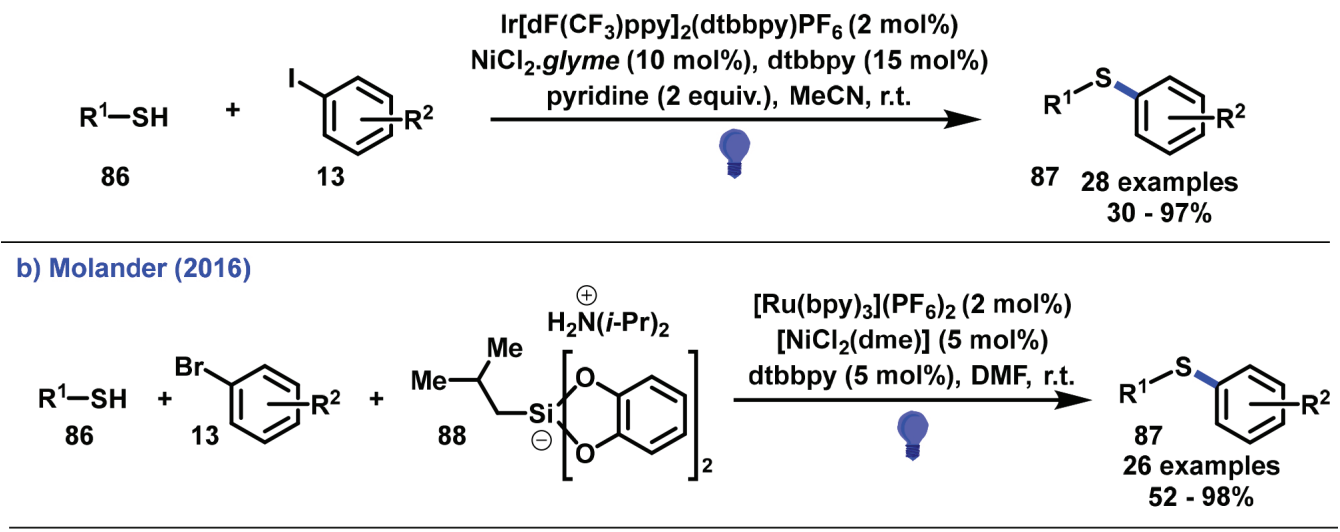

c) Molander e Gutierrez (2018)
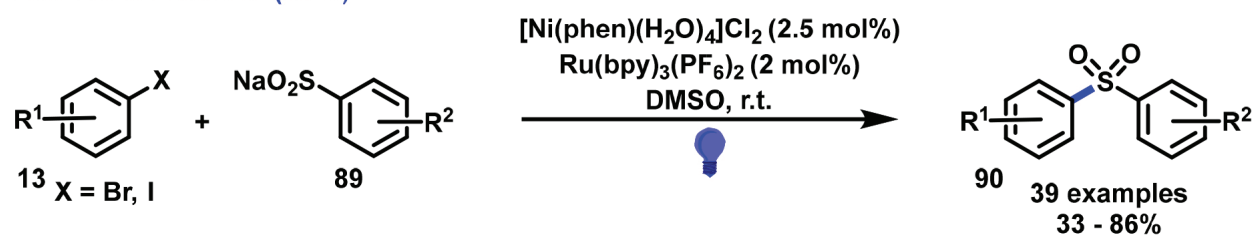

Scheme 16. Synergistic combination of Ni-catalysis and metal photocatalyst for the formation of C-S bonds (dme = dimethoxyetane; phen = 9,10-phenanthroline)

species to $\mathrm{Ni}(\mathrm{I})$ and cyclic voltammetry experiments supported the porposed mechanism (Scheme 16). ${ }^{190}$

In the same year, Molander also reported a thietherification process of aryl bromides 13. Following this strategy, a sulfur radical is generated from a hydrogen atom transfer from the alkyl radical resulting from the oxidation of isobutyl bis(catecolate)silicate $\mathbf{8 8}$ by the excited species $* \mathrm{Ru}(\mathrm{II})$ and a thiol $\mathbf{8 6}$. This sulfur radical reacts with the Ni catalyst and the aryl bromide $\mathbf{1 3}$ to afford the corresponding arylthioether $\mathbf{8 7}$ (Scheme 16b). ${ }^{191}$ It was possible to use primary, secondary or tertiary thiols in this transformation; and high selectivity was observed for the C-S coupling in the presence of a variety of functional groups.

Recently, Gutierrez, Molander and co-workers reported a method involving Ni catalysis and a Ru photoredox catalyst for the construction of aryl and heteroaryl sulfones $\mathbf{9 0}$, starting from aryl halides 13 and sulfinate salts $\mathbf{8 9}$ (Scheme 16c). ${ }^{192}$ A sulfonyl radical is formed from the oxidation promoted by the $* \mathrm{Ru}(\mathrm{II})$ species (thus generating a $\mathrm{Ru}(\mathrm{I})$ species) and adds to the $\mathrm{Ni}(0)$ species, thus generating a $\mathrm{Ni}(\mathrm{I})$ complex, that undergoes an oxidative addition in the presence of the aryl halide 13. Finally, the resulting Ni(III) species undergoes reductive elimination to afford the sulfone $\mathbf{9 0}$ and generates a $\mathrm{Ni}(\mathrm{I})$ catalyst, that is finally reduced by the previously formed $\mathrm{Ru}(\mathrm{I})$ species to regenerate both $\mathrm{Ni}(0)$ and $\mathrm{Ru}(\mathrm{II})$ catalysts.

In addition, other similar photochemically-promoted crosscoupling reactions leading to the preparation of other sulfones have been also reported by Rueping ${ }^{193}$ and Manolikakes. ${ }^{194}$

Molander and co-workers explored the interplay between $\mathrm{Ni}$ catalysis and photoredox catalysis to react aryl bromides $\mathbf{1 3}$ with SH-containing biomolecules $\mathbf{9 1}$ to afford the corresponding crosscoupled products $\mathbf{9 2}$, in the absence of any protecting groups. The mechanism of this transformation is proposed to proceed by the generation of a sulfur radical 93 from a hydrogen atom transfer event between the biomolecule 91 and the alkyl radical 43, which in turn is derived from the $* \mathrm{Ru}(\mathrm{II})$-promoted oxidation of the silicon reagent $\mathbf{8 8}$. Then, the thioradical 93 adds to the $\mathrm{Ni}(0)$ catalyst 95 to form the $\mathrm{Ni}(\mathrm{I})$ species 96. This intermediate undergoes oxidative addition with the starting aryl halide $\mathbf{1 3}$ to produce the $\mathrm{Ni}(\mathrm{III})$ intermediate $\mathbf{9 7}$. Finally, reductive elimination leads to the formation of the cross-coupled product 92, while producing $\mathrm{Ni}(\mathrm{I})$ catalyst 98 . This catalytic species is reduced by the $\mathrm{Ru}(\mathrm{I})$ photoredox catalyst to regenerate both the $\mathrm{Ni}(0)$ catalyst 95 and the $\mathrm{Ru}(\mathrm{II})$ photoredox catalyst (Scheme 17). ${ }^{195}$ This method can be performed in gram-scale and the scope of this transformation has been demonstrated to the use of L-glutathione, Tiopronin, D-penicillamine, biological probes, and pharmaceuticals.

In 2018, MacMillan and co-workers reported a protocol for a decarboxylative hydroalkylation of internal alkynes $\mathbf{9 9}$ using carboxylic acids 100, in order to produce the corresponding trisubstituted alkenes 101. Accordingly, this transformation involves the * $\operatorname{Ir}(\mathrm{III})$-promoted oxidation of carboxylic acids $\mathbf{1 0 0}$, followed by a decarboxylation event to generate the corresponding alkyl radical 102. Upon generation of the alkyl radical 102, * $\operatorname{Ir}(\mathrm{III})$ is reduced to $\operatorname{Ir}(\mathrm{II})$, which is then oxidized back to Ir(III) by transferring one electron to $\mathrm{Ni}$ (II) species $\mathbf{1 0 3}$, thus forming a $\mathrm{Ni}(\mathrm{I})$ intermediate $\mathbf{1 0 4}$. The generated alkyl radical $\mathbf{1 0 2}$ adds onto the $\mathrm{Ni}(\mathrm{I})$ intermediate $\mathbf{1 0 4}$ to afford the corresponding $\mathrm{Ni}$ (II) species 105. Subsequently, 1,2-insertion onto the internal alkyne 99 leads to $\mathrm{Ni}$ (II) intermediate 106, which undergoes protodemetallation to produce the desired trisubstituted alkene $\mathbf{1 0 1}$ and $\mathrm{Ni}$ (II) catalyst $\mathbf{1 0 3}$. Finally, a SET involving Ir(II) photocatalyst and $\mathrm{Ni}$ (II) intermediate 103 regenerates $\mathrm{Ni}(\mathrm{I})$ starting catalyst species 104 (Scheme 18). Control experiments have shown that the observed regioselectivity of the 1,2-migration involving $\mathrm{Ni}$ intermediate $\mathbf{1 0 5}$ and alkyne $\mathbf{9 9}$ depends on the size of the groups envolved. ${ }^{196}$

\section{Applications employing $\mathrm{Au}$}

Oxidative additions between $\mathrm{Au}(\mathrm{I})$ and aryl halides are challenging ${ }^{197}$ and the redox pair $\mathrm{Au}(\mathrm{I}) / \mathrm{Au}(\mathrm{III})$ is generally not easily interconverted. ${ }^{198}$ Among some of the catalytic cycles reported for cross-coupling reactions involving gold, this challenging redox interconversion can be performed in the presence of an oxidizing agent or a photoredox catalyst. The merger of Au catalysis with photoredox catalysis has been reported by the first time by Glorius and co-workers in 2013. ${ }^{199}$ They employed aryldiazonium salts $\mathbf{1 7}$ as the source of aryl radicals $\mathbf{1 9}$, that were generated for the intramolecular oxy/aminoarylation of alkenes. The excited photoredox catalyst * Ru(II) reduces the aryldiazonium salt $\mathbf{1 7}$ to produce aryl radicals 19, while $\mathrm{Au}(\mathrm{I})$ catalyst $\mathbf{1 0 9}$ promotes an intramolecular cyclization 
Molander (2018)

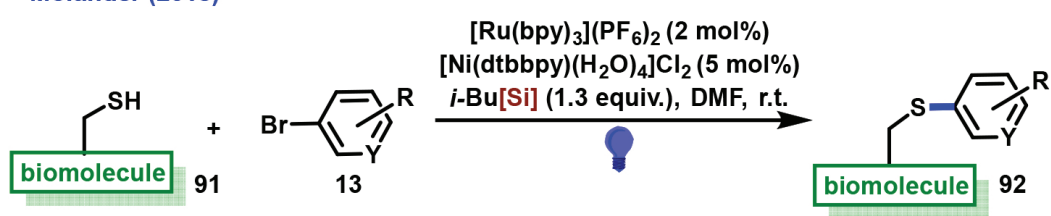

$\boldsymbol{i}-\mathrm{Bu}[\mathrm{Si}]=$

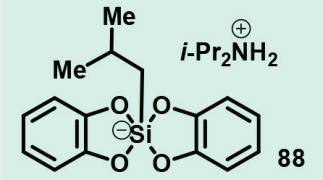

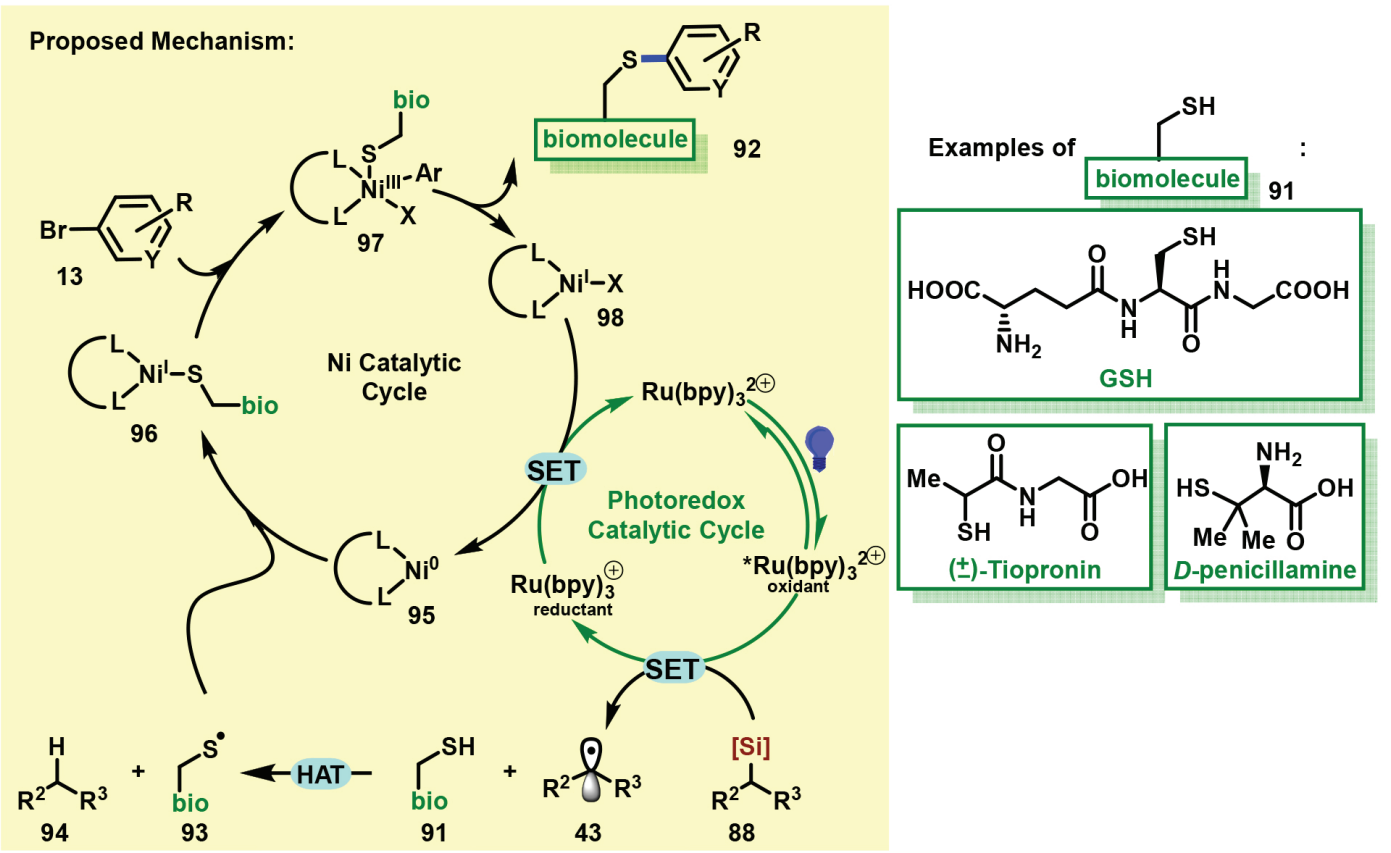

Scheme 17. Thioarylation of peptides and biomolecules by means of Ni catalysis and photoredox catalysis

$\mathrm{R}^{2}=\mathrm{R}^{3}+\prod^{\mathrm{R}^{1}} \prod_{100}^{\mathrm{OH}}$
$\operatorname{Ir}\left[\mathrm{dF}\left(\mathrm{CF}_{3}\right) \mathrm{ppy}\right]_{2}$ (dtbbpy) $\mathrm{PF}_{6}(2 \mathrm{~mol} \%)$

$$
\mathrm{NiCl}_{2} \cdot \mathrm{dtbbpy}(10 \mathrm{~mol} \%)
$$

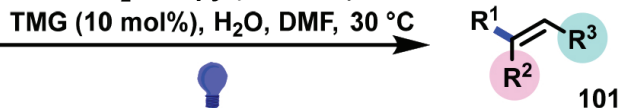

33 examples

$41-85 \%$

Proposed Mechanism:

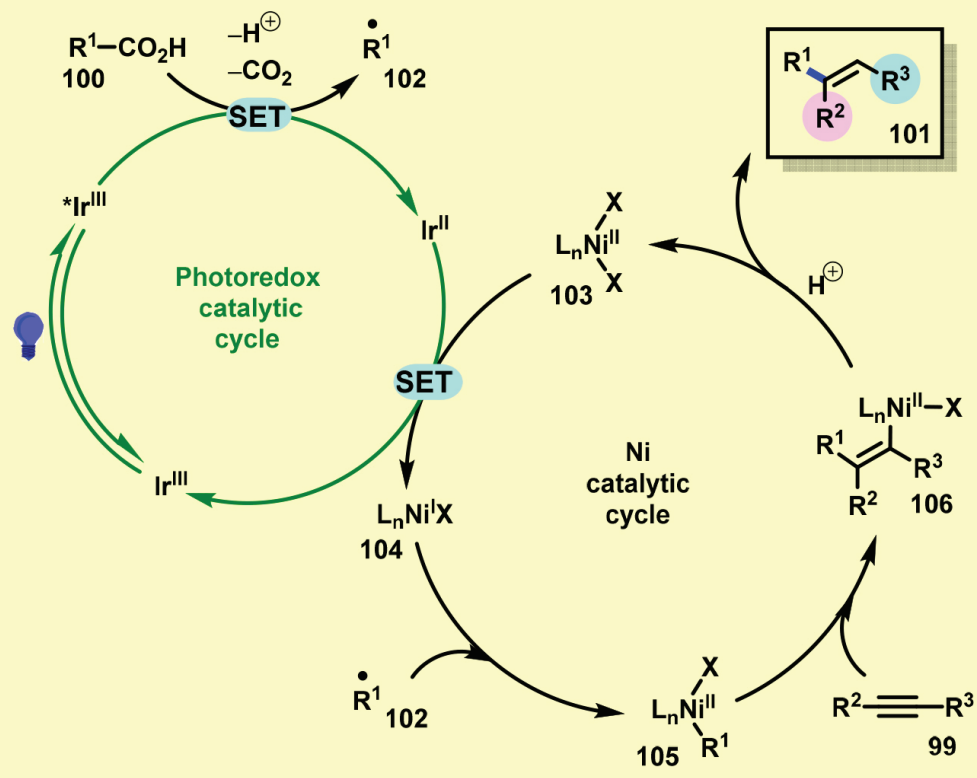

Scheme 18. Decarboxylative hydroalkylation of carboxylic acids onto internal alkynes employing a synergistic combination of Ni-catalysis and photoredox catalysis (TMG =1,1,3,3-tetramethylguanidine) 
event of starting substrate $\mathbf{1 0 7}$, leading to organogold intermediate 110. The $\mathrm{Au}(\mathrm{I})$ intermediate 110 reacts with aryl radical 19 to afford $\mathrm{Au}(\mathrm{II})$ intermediate 111, which upon an electron transfer event converting $\mathrm{Ru}(\mathrm{III})$ into starting $\mathrm{Ru}(\mathrm{II})$, generates $\mathrm{Au}(\mathrm{III})$ intermediate 112. Finally, reductive elimination of $\mathbf{1 1 2}$ leads to the cross coupled product 108 and regenerates the $\mathrm{Au}(\mathrm{I})$ catalyst 109 (Scheme 19). Remarkably, the formation of Au(III)-Ar complexes, such as 112, typically produces a fast reductive elimination, thus avoiding protodeauration compounds and a potentially competing homodimerization pathway.

In contrast to the use of strong oxidizing agents employed in stoichiometric amounts for other gold-catalyzed cross-coupling protocols, ${ }^{200}$ the merger with photocatalysis allows the use of mild conditions, based on an overall neutral redox conditions.

Inspired by the early work of Sanford ${ }^{167}$ Glorius and Toste have demonstrated that aryl radicals $\mathbf{1 9}$ generated by photoredox catalysis from aryldiazonium salts $\mathbf{1 7}$ could be employed in gold-catalyzed reactions in a variety of transformations, such as arylation of alkynes 113 or $\mathbf{1 1 9} ;{ }^{201,202} \mathrm{H}$-phosphonates $\mathbf{1 1 5} ;{ }^{203}$ in arylative-ring-expansions using substrates 117;204 arylation-hydration sequences usig alkynes 99 and $\alpha$-arylation within Meyer-Shuster rearrangements of propargyl alcohols $\mathbf{1 2 1}^{205}$ (Scheme 20).

Although the synergistic combination of metal catalysis and photoredox catalysis has been mainly composed of contributions employing $\mathrm{Cu}, \mathrm{Pd}, \mathrm{Ni}$ and $\mathrm{Au}$ as metal catalysts, other protocols involving $\mathrm{Co}^{206} \mathrm{Ru}^{207}$ and $\mathrm{Rh}^{208}$ have been also reported for $\mathrm{C}-\mathrm{H}$ functionalization processes, $\mathrm{C}-\mathrm{C}$ and $\mathrm{C}-\mathrm{O}$ couplings and oxidation reactions.

\section{CONCLUSIONS}

Since 2011, the synergism involving photoredox catalysis and metal catalysis has been used as a powerful strategy for the development of new synthetic technologies. In this context, advantages and disadvantages generally involve low catalyst loadings and potential toxicity issues associated to the use of metals, or sustainability aspects when rare metals are employed, respectively. Metal catalysis is a well-established field, which did not cease to evolve over the years. Nevertheless, the involvement of SET processes has allowed the development of new cross coupling protocols, most remarkably due to the involvement of new oxidation states of key catalytic intermediates (which are not as easily generated by other strategies). It is likely that the merger of both catalytic strategies will become increasingly important in the next years. It is possible to anticipate that new reactivity profiles will continue to be unlocked, proceeding via mild reaction conditions and significantly contributing to the broad advancement of organic synthesis.

Although economic aspects are always important to be taken into account, looking at the great number of publications appearing every year in the field of photoredox catalysis and metal catalysis in general; and the price of most common promoters, such as classical photoredox catalysts or $\mathrm{Ni}$ catalysts, their values do not seem to be a dominant barrier here for the advancement of this chemistry. Creativity and understanding the reactivity aspects underpinning these fields are far more important ingredients for the development of useful new protocols.

Glorius (2013)
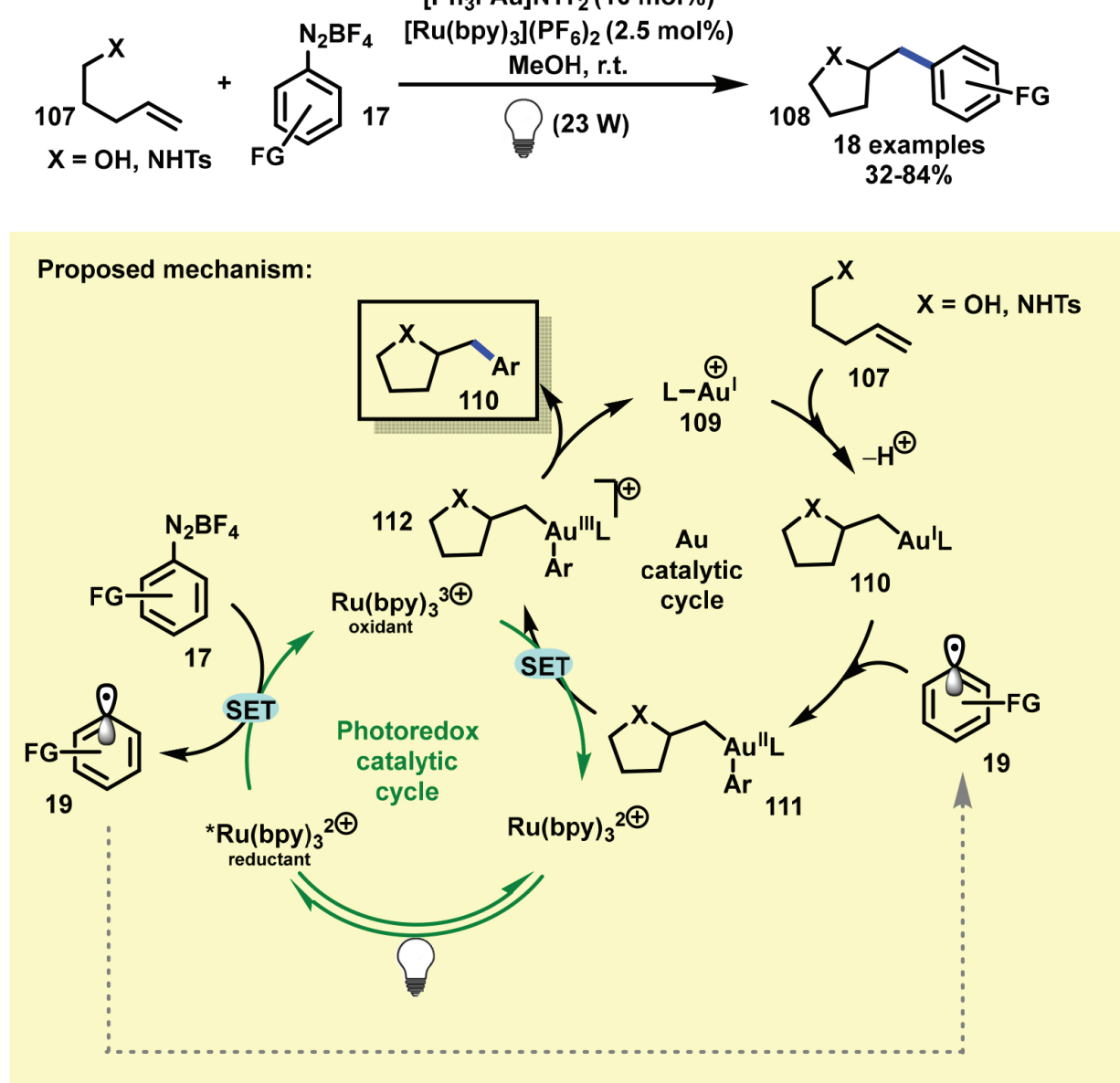

Scheme 19. Oxi/amino-arylation of alkenes through the merger of gold catalysis and photoredox catalysis 
a) Toste

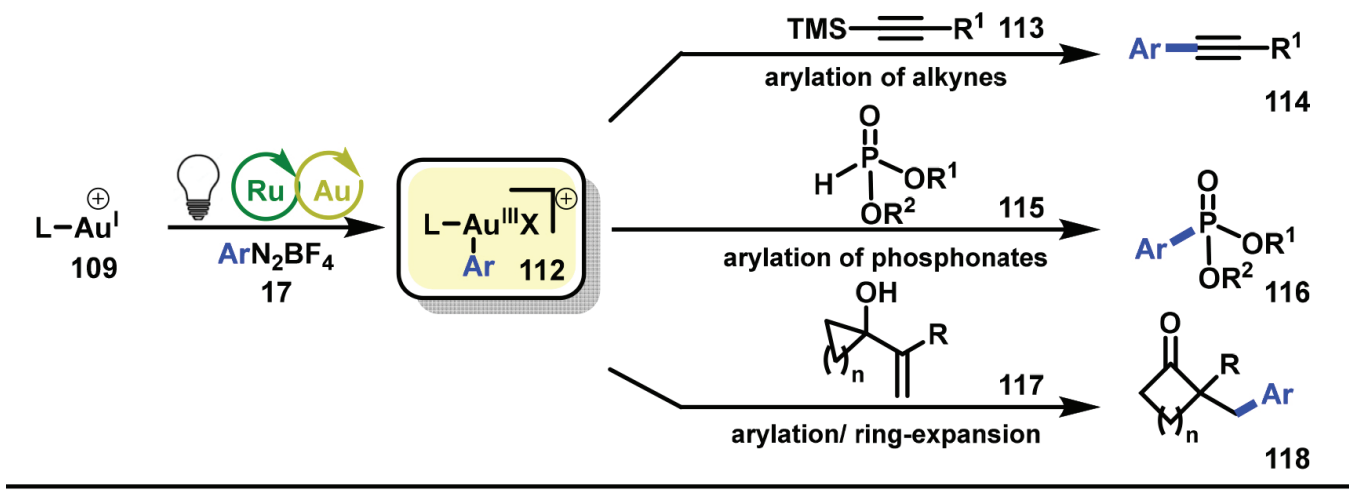

b) Glorius

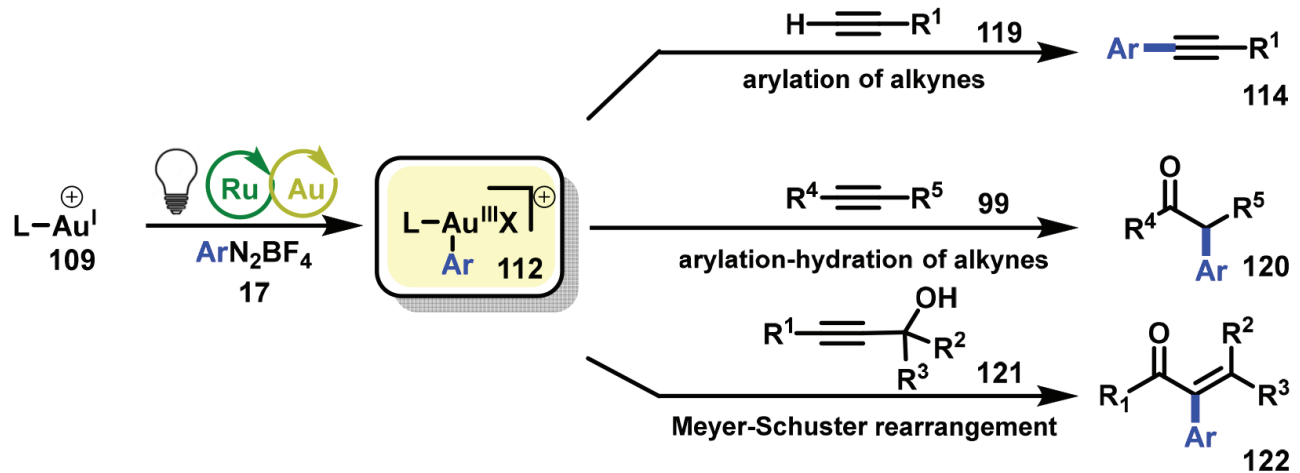

Scheme 20. Transformations performed by the groups of Toste and Glorius via the synergistic combination of gold catalysis and photoredox catalysis

\section{ACKNOWLEDGMENTS}

The authors acknowledge Fapesp for a PhD Fellowship to A. A. G. F. (2017/22164-6) and a Research Grant to I. D. J. (2017/24017-0).

\section{REFERENCES}

1. Cadet de Gassicourt, L. C.; Mem. Math. Phys. 1760, 3, 623.

2. Bunsen, R. W.; Annalen 1837, 24, 271; Bunsen, R. W.; Ann. Phys. 1837, 40, 219; Bunsen, R. W.; Annalen 1839, 31, 175; Bunsen, R. W.; Annalen 1841, 37, 1; Bunsen, R. W.; Annalen 1842, 42, 14; Bunsen, R. W.; Annalen 1843, 46, 1 .

3. Zeise, W. C.; Ann. Phys. 1827, 9, 632.

4. Liebig, J.; Annalen 1837, 23, 12. See also: Thayer, J. S.; J. Chem. Educ. 1969, 46, 442.

5. Birnbaum, K.; Annalen 1868, 145, 68. See also: Winstein, S.; Lucas, H. J.; J. Am. Chem. Soc. 1938, 60, 836.

6. Dewar, M. J. S.; Bull. Soc. Chim. Fr. 1951, 18, C71; Dewar, M. J. S.; Bull. Soc. Chim. Fr. 1951, C79.

7. Chatt, J.; Duncanson, L. A.; J. Chem. Soc. 1953, 2939.

8. Frankland, E.; J. Chem. Soc. 1849, 2, 263.

9. Frankland, E.; Phil. Trans. 1852, 142, 417.

10. The preparation of $\mathrm{SnEt}_{4}$ has been also reported by Löwig in the same year, although probably impure. See: Löwig, C.; Annalen 1852, 84, 309.

11. Frankland, E.; Prac. Roy. Inst. 1864, 4, 309.

12. Friedel, C.; Crafts, J. M.; Annalen 1863, 127, 28.

13. Schützenberger, M. P.; Annales 1868, 15, 100.

14. Mond, L.; J. Chem. Soc. 1890, 57, 749.

15. Mond, L.; Quincke, F.; J. Chem. Soc. 1891, 59, 604.

16. Berthelot, M.; C. R. Acad. Sci. 1891, 112, 1343.

17. Wöhler, F.; Phys. Chem. 1828, 88, 253.
18. Wurtz, A.; Ann. Chim. Phys. 1855, 44, 279.

19. Glaser, C.; Ber. Dtsch. Chem. Ges. 1869, $2,422$.

20. Phillips, F. C.; Am. Chem. J. 1894, 16, 255; Phillips, F. C.; Z. Anorg. Chem. 1894, 6, 213.

21. Barbier, P.; C. R. Acad. Sci. 1899, 128, 110.

22. For more recent examples, see also: Chattopadhyay, A.; J. Org. Chem. 1996, 61, 6104; Jõgi, A.; Mäeorg, U.; Molecules 2001, 6, 964.

23. Grignard, V.; C. R. Acad. Sci. 1900, 130, 1322. See also: Grignard, V.; Courtot, C.; Compt. Rend. Acad. Sci. 1914, 158, 1763.

24. For a more recent review, see: Seyferth, D.; Organometallics 2009, 28, 1598.

25. Taylor, H.; J. Am. Chem. Soc. 1944, 66, 1615; Morachevskii, A. G.; Russ. J. Appl. Chem. 2004, 77, 1909.

26. Ullman, F.; Bielecki, J.; Chem. Ber. 1901, 2174.

27. Ullman, F.; Chem. Ber. 1903, 2382.

28. See also C-O coupling: Ullmann, F.; Chem. Ber. 1904, 853; Ullmann, F.; Sponagel, P.; Chem. Ber. 1905, 2211.

29. Ertl, G.; Angew. Chem., Int. Ed. 2009, 48, 6600.

30. Schlenck, W.; Holtz, J.; Ber. Dtsch. Chem. Ges. 1917, 50, 262

31. Ziegler, K.; Colonius, H.; Justus Liebigs Ann. Chem. 1930, 479, 135.

32. For a historical review on the chemistry of Li and organolithium compounds, see: Wietelmann, U.; Klett, J.; Z. Anorg. Allg. Chem. 2018, 644, 194.

33. For the seminal work, see: Haber, F.; Le Rossignol, R.; Z. Elektrochem. Angew. Phys. Chem. 1913, 19, 53.

34. Baranski, A.; Kotarba, A.; Lagan, J. M.; Pattek-Janczyk, A.; Pyrczak, E.; Reizer, A.; Appl. Catal., A 1994, 112, 13; Rayment, T.; Schlögl, R.; Thomas, J. M.; Ertl, G.; Nature 1985, 315, 311.

35. Mittasch, A.; Adv. Catal. 1950, $2,81$.

36. For a review, see: Kandemir, T.; Schuster, M. E.; Senyshyn, A.; Behrens, M.; Schlögl, R.; Angew. Chem., Int. Ed. 2013, 52, 12723. 
37. Apodaca, L. E.; U. S. Geological Survey 2011.

38. The Development of Catalysis: A History of Key Processes and Personas in Catalytic Science and Technology; Zecchina, A.; Califano, S., eds.; Wiley-VCH: New York, 2017, pp. 161-174.

39. Meerwein, H.; Büchner, E.; van Emster, K.; J. Prakt. Chem. 1939, 237.

40. Reppe, W.; Schweckendiek, W. J.; Justus Liebigs Ann. Chem. 1948, 560, 104.

41. See also: Galan, B. R.; Rovis, T.; Angew. Chem., Int. Ed. 2009, 48, 2830, and references therein.

42. Kealy, T. J.; Pauson, P. L.; Nature 1951, 1039.

43. Wilkinson, G.; Rosenblum, M.; Whiting, M. C.; Woodward, R. B.; J. Am. Chem. Soc. 1952, 2125. See also: Miller, S. A.; Tebboth, J. A.; Tremaine, J. F.; J. Chem. Soc. 1952, 632.

44. For a recent historical perspective, see: Seeman, J. I.; Cantrill, S.; Nat. Chem. 2016, 193.

45. Gilman, H.; Jones, R. G.; Woods, L. A.; J. Org. Chem. 1952, 1630.

46. For a discussion on the structure of Gilman cuprates, see: Hope, H.; Olmstead, M. M.; Power, P. P.; Sandell, J.; Xu, X.; J. Am. Chem. Soc. 1985, 107, 4337.

47. Ziegler, K.; Holzcamp, E.; Breil, H.; Martin H.; Angew. Chem. 1955 , 16, 426; Natta, G.; Pino, P.; Corradini, P.; Danusso, F.; Mantica, E.; Mazzanti, G.; Moraglio, G.; J. Am. Chem. Soc. 1955, 77, 1708; Natta, G.; J. Polym. Sci. 1955, 16, 143.

48. For reviews, see: Claverie, J. P.; Schaper, F.; MRS Bull. 2013, 38, 213; Wilke, G.; Angew. Chem., Int. Ed. 2003, 42, 5000; Eisch, J. J.; Organometallics 2012, 31, 4917.

49. Hodgkin, D. C.; Kamper, J.; Mackay, M.; Pickworth, J.; Trueblood, K. N.; White, J. G.; Nature 1956, 178, 64.

50. Noltes, J. G.; van der Kerk, J. M.; Chem. Ind. 1959, 294.

51. For reviews, see: Kuivila, H. G.; Synthesis 1970, 10, 499; Neumann, W. P.; Synthesis 1987, 665.

52. Kuivila, H. G.; Menapace, L. W.; Warner, C. R.; J. Am. Chem. Soc. 1962, 84, 3584.

53. Barton, D. H. R.; McCombie, S. W.; J. Chem. Soc., Perkin Trans. 1 1975, 16, 1574. See also: Barton, D. H. R.; Motherwell, W. B.; Pure Appl. Chem. 1981, 53, 15 .

54. Barton, D. H. R.; Crich, D.; Motherwell, W. B.; J. Chem. Soc., Chem. Commun. 1983, 939. See also: Barton, D. H. R.; Crich, D.; Motherwell, W. B.; Tetrahedron 1985, 41, 3901.

55. Smidt, J.; Hafner, W.; Jira, R.; Sedlmeier, J.; Sieber, R.; Rüttinger, R.; Kojer, H.; Angew. Chem. 1959, 5, 176; Smidt, J.; Sieber, R.; Angew. Chem. 1959, 71, 626.

56. See also: Lloid, W. G.; Luberoff, B. J.; J. Org. Chem. 1969, 34, 3949; Smidt, J.; Hafner, W.; Jira, R.; Siber, R.; Sedlmeier, J.; Sabel, A.; Angew. Chem., Int. Ed. 1962, 1, 80; Keith, J. A.; Henry, P. M.; Angew. Chem., Int. Ed. 2009, 48, 9038; Jira, R.; Angew. Chem., Int. Ed. 2009, 48, 9034.

57. Tsuji, J.; Takahashi, H.; Morikawa, M.; Tetrahedron Lett. 1965, 49, 4387.

58. Trost, B. M.; Fullerton, T. J.; J. Am. Chem. Soc. 1973, 292.

59. Trost, B. M.; Van Vranken, D. L.; Bingel, C.; J. Am. Chem. Soc. 1992, 114,9327

60. Osborn, J. A.; Jardine, F. H.; Young, J. F.; Wilkinson, G.; J. Chem. Soc. A 1966, 1711.

61. Calderon, N.; Chen, H. Y.; Scott, K. W.; Tetrahedron Lett. 1967, 34, 3327.

62. Pennella, F.; Banks, R. L.; Bailey, G. C.; Chem. Commun. 1968, 1548.

63. Heck, R. F.; J. Am. Chem. Soc. 1968, 90, 5518.

64. Mizoroki, T.; Mori, K.; Ozaki, A.; Bull. Chem. Soc. Jpn. 1971, 44, 581.

65. Gol'dshleger, N. F.; Tyabin, M. B.; Shilov, A. E.; Shteinman, A. A.; Zh. Fiz. Khim. 1969, 43, 2174. See also: Shteinman, A. A.; J. Organometal. Chem. 2015, 793, 34; Shilov, A. E.; Shul'pin, G. B.; Chem. Rev. 1997 97,2879
66. Hérisson, J. L.; Chauvin, Y.; Die Makromolekulare Chem. 1970, 141, 161.

67. For further discussions, see also: Calderon, N.; Acc. Chem. Res. 1972, 5, 127, and references therein; Bailey, G. C.; Catal. Rev. 1970, 3, 37; Grubbs, R. H.; Burk, P. L.; Carr, D. D.; J. Am. Chem. Soc. 1975, 97, 3265.

68. Corriu, R. J. P.; J. Chem. Soc., Chem. Commun. 1972, 144.

69. Tamao, K.; Kiso, Y.; Sumitani, K.; Kumada, M.; J. Am. Chem. Soc. 1972, 9268; Tamao, K.; Sumitani, K.; Kumada, M.; J. Am. Chem. Soc. 1972, 4374.

70. Sonogashira, K.; Tohda, Y.; Hagihara, N.; Tetrahedron Lett. 1975, 50, 4467.

71. Baba, S.; Negishi, E.-i.; J. Am. Chem. Soc. 1976, 98, 6729; Negishi, E.-i.; Van Horn, D. E.; J. Am. Chem. Soc. 1977, 99, 3168; Negishi, E.-i.; King, A. O.; Okukado, N.; J. Org. Chem. 1977, 42, 1821.

72. Kosugi, M.; Shimizu, Y.; Migita, T.; Chem. Lett. 1977, 1423; Kosugi, M.; Sasazawa, K.; Shimizu, Y.; Migita, T.; Chem. Lett. 1977, 301. For the use of a Rh derivative as catalyst, see also: Kosugi, M.; Shimizu, Y.; Migita, T.; J. Organomet. Chem. 1977, 129, C36.

73. Milstein, D.; Stille, J. K.; J. Am. Chem. Soc. 1978, 100, 3636.

74. Miyaura, N.; Yamada, K.; Suzuki, A.; Tetrahedron Lett. 1979, 36, 3437; Miyaura, N.; Suzuki, A.; J. Chem. Soc., Chem. Commun. 1979, 866.

75. Seyferth, D.; Davison, A.; Science 1973, 182, 699.

76. Mortreux, A.; Blanchard, M.; J. Chem. Soc., Chem. Commun. 1974, 786.

77. Namy, J. L.; Girard, P.; Kagan, H.; Nouv. J. Chim. 1977, 1, 5. See also: Girard, P.; Namy, J. L.; Kagan, H. B.; J. Am. Chem. Soc. 1980, 102, 2693.

78. For reviews on the use of $\mathrm{SmI}_{2}$ in organic synthesis, see: Nicolaou, K. C.; Ellery, S. P.; Chen, J. S.; Angew. Chem., Int. Ed. 2009, 7140; Krief, A.; Laval, A.-M.; Chem. Rev. 1999, 99, 745; Szostak, M.; Spain, M.; Procter, D. J.; Chem. Soc. Rev. 2013, 42, 9155.

79. Crabtree, R. H.; Mihelcic, J. M.; Quirk, J. M.; J. Am. Chem. Soc. 1979, 101,7738

80. Wengrovius, J. H.; Sancho, J.; Schrock, R. R.; J. Am. Chem. Soc. 1981, 103, 3932

81. Dietrich-Buchecker, C. O.; Sauvage, J. P.; Tetrahedron Lett. 1983, 24, 5095. See also: Dietrich-Buchecker, C. O.; Sauvage, J. P.; J. Am. Chem. Soc. 1984, 106, 3043.

82. Kulinkovich, O. G.; Sviridov, S. V.; Vasilevski, D. A.; Pritytskaya, T. S.; Zh. Org. Khim. 1989, 25, 2244. See also: Kulinkovich, O. G.; Sviridov, S. V.; Vasilevski, D. A.; Synthesis 1991, 3, 224.

83. Miyashita, A.; Yasuda, A.; Takaya, H.; Toriumi, K.; Ito, T.; Souchi, T.; Noyori, R.; J. Am. Chem. Soc. 1980, 102, 7932. See also: Noyori, R.; Ohta, M.; Hsiao, Y.; Kitamura, M.; J. Am. Chem. Soc. 1986, 108, 7117; Kitamura, M.; Ohkuma, T.; Inoue, S.; Sayo, N.; Kumobayashi, H.; Akutagawa, S.; Ohta, T.; Takaya, H.; Noyori, R.; J. Am. Chem. Soc. 1988, 110, 629; Kitamura, M.; Tokunaga, M.; Ohkuma, T.; Noyori, R.; Tetrahedron Lett. 1991, 32, 4163.

84. Narasaka, K.; Inoue, M.; Okada, N.; Chem. Lett. 1986, 1109.

85. Seebach, D.; Beck, A. K.; Imwinkelried, R.; Roggo, S.; Wonnacott, A.; Helv. Chim. Acta 1987, 70, 954

86. Jacobsen, E. N.; Markó, I.; Mungall, W. S.; Schröder, G.; Sharpless, K. B.; J. Am. Chem. Soc. 1988, 110, 1968.

87. Zhang, W.; Loebach, J. L.; Wilson, S. R.; Jacobsen, E. N.; J. Am. Chem. Soc. 1990, 112, 2801

88. Irie, R.; Noda, K.; Ito, Y.; Katsuki, T.; Tetrahedron Lett. 1991, 32, 1055; Irie, R.; Noda, K.; Ito, Y.; Matsumoto, N.; Katsuki, T.; Tetrahedron Asymmetry 1991, 2, 481.

89. Arduengo, III, A. J.; Harlow, R. L.; Kline, M.; J. Am. Chem. Soc. 1991 , 113,361 .

90. Larock, R. C.; Yum, E. K.; J. Am. Chem. Soc. 1991, 113, 6689.

91. Bazan, G. C.; Oskam, J. H.; Cho, H.-N.; Park, L. Y.; Schrock. R. R.; J. Am. Chem. Soc. 1991, 113, 6899.

92. Sasai, H.; Suzuki, T.; Arai, S.; Arai, T.; Shibasaki, M.; J. Am. Chem. Soc. 1992, 114, 4418. 
93. See for instance, Michael addition: Sasai, H.; Arai, T.; Satow, Y.; Houk, K. N.; Shibasaki, M.; J. Am. Chem. Soc. 1995, 117, 6194; Diels-Alder: Morita, T.; Arai, T.; Sasai, H.; Shibasaki, M.; Tetrahedron: Asymmetry 1998, 9, 1445; Phospho-Mannich: Sasai, H.; Arai, S.; Tahara, Y.; Shibasaki, M.; J. Org. Chem. 1995, 60, 6656.

94. Nguyen, S. T.; Johnson, L. K.; Grubbs, R. H.; J. Am. Chem. Soc. 1992, 114, 3974. See also: Nguyen, S. T.; Grubbs, R. H.; J. Am. Chem. Soc. 1993, 115, 9858. See also: Schwab, P.; France, M. B.; Ziller, J. W.; Grubbs, R. H.; Angew. Chem., Int. Ed. 1995, 34, 2039; Schwab, P.; Grubbs, R. H.; Ziller, J. W.; J. Am. Chem. Soc. 1996, 118, 100.

95. Scholl, M.; Trnka, T. M.; Morgan, J. P.; Grubbs, R. H.; Tetrahedron Lett. 1999, 40, 2247. See also: Scholl, M.; Ding, S.; Lee, C. W.; Grubbs, R. H.; Org. Lett. 1999, 1, 953.

96. For a selection of reviews, see: Hoveyda, A. H.; Zhugralin, A. R.; Nature 2007, 450, 243; Connon, S. J.; Blenchert, S.; Angew. Chem., Int. Ed. 2003, 42, 1900; Ogba, O. M.; Warner, N. C.; O’Leary, D. J.; Grubbs, R. H.; Chem. Soc. Rev. 2018, 47, 4510.

97. Chauvin, Y.; Angew. Chem., Int. Ed. 2006, 45, 3740; Schrock, R.; Angew. Chem., Int. Ed. 2006, 45, 3748; Grubbs, R.; Angew. Chem., Int. Ed. 2006, 45, 3760; Casey, C. P.; J. Chem. Educ. 2006, 83, 192.

98. Keck, G. E.; Tarbet, K. H.; Geraci, L. S.; J. Am. Chem. Soc. 1993, 115, 8467; Keck, G. E.; Krishnamurthy, D.; Grier, M. C.; J. Org. Chem. 1993, 58, 6543; Keck, G. E.; Geraci, L. S.; Tetrahedron Lett. 1993, 34, 7827.

99. Paul, F.; Patt, J.; Hartwig, J. F.; J. Am. Chem. Soc. 1994, 116, 5969.

100. Guram, A. S.; Buchwald, S. L.; J. Am. Chem. Soc. 1994, 116, 7901.

101. Ruiz-Castillo, P.; Buchwald, S. L.; Chem. Rev. 2016, 116, 12564.

102. Old, D. W.; Wolfe, J. P.; Buchwald, S. L.; J. Am. Chem. Soc. 1998, 120, 9722. See also: Sadighi, J. P.; Harris, M. C.; Buchwald, S. L.; Tetrahedron Lett. 1998, 39, 5327.

103. For a review, see: Martin, R.; Buchwald, S. L.; Acc. Chem. Res. 2008, $41,1461$.

104. Examples in C-N coupling: Surry, D. S.; Buchwald, S. L.; Chem. Sci. 2011, 2, 27; Surry, D. S.; Buchwald, S. L.; Angew. Chem., Int. Ed. 2008, 47, 6338. Examples in Negishi coupling: Milne, J. E.; Buchwald, S. L.; J. Am. Chem. Soc. 2004, 126, 13028. Examples in $\alpha$-arylation of ketones: Fox, J. M.; Huang, X.; Chieffi, A.; Buchwald, S. L.; J. Am. Chem. Soc. 2000, 122, 1360. Examples in C-O coupling: Burgos, C. H.; Barder, T. E.; Huang, X.; Buchwald, S. L.; Angew. Chem., Int. Ed. 2006, $45,4321$.

105. Martínez, L. E.; Leighton, J. L.; Carsten, D. H.; Jacobsen, E. N.; J. Am. Chem. Soc. 1995, 117, 5897.

106 Herrmann, W. A.; Elison, M.; Fischer, J.; Köcher, C.; Artus, G. R. J.; Angew. Chem., Int. Ed. 1995, 34, 2371.

107. Li, G.; Chang, H.-T.; Sharpless, K. B.; Angew. Chem., Int. Ed. 1996, 35 , 451.

108. Periana, R. A.; Taube, D. J.; Gamble, S.; Taube, H.; Satoh, T.; Fuji, H.; Science 1998, 280, 560 .

109. Pastine, S. J.; McQuaid, K. M.; Sames, D.; J. Am. Chem. Soc. 2005, 127, 12180.

110. For selected reviews, see: Godula, K.; Sames, D.; Science 2006, 312, 67; Haibach, M. C.; Seidel, D.; Angew. Chem., Int. Ed. 2014, 53, 5010; Peng, B.; Maulide, N.; Chem. - Eur. J. 2013, 19, 13274.

111. Li, Z.; Bohle, S.; Li, C.-J.; Proc. Nat. Acad. Sci. U. S. A. 2006, 103, 8928.

112. See also: Li, C.-J.; Acc. Chem. Res. 2009, 42, 335; Girard, S. A.; Knauber, T.; Li, C.-J.; Angew. Chem., Int. Ed. 2014, 53, 74.

113. Chen, M. S.; White, C.; Science 2007, 318, 783. See also: Chen, M. S.; White, M. C.; Science 2010, 327, 566.

114. Leow, D.; Li, G.; Mei, T.-S.; Yu, J.-Q.; Nature 2012, 486, 518. For an extension of the work, see: Zhang, Z.; Tanaka, K.; Yu, J.-Q.; Nature 2017, 543, 538 .

115. Liao, K.; Negretti, S.; Musaev, D. G.; Bacsa, J.; Davies, H. M. L.; Nature 2016, 533, 230; See also: Liao, K.; Pickel, T. C.; Boyarskikh, V.;
Bacsa, J.; Musaev, D. G.; Davies, H. M. L.; Nature 2017, 551, 609.

116. For a review, see: Davies, H. M. L.; Manning, J. R.; Nature 2008, 451 , 417.

117. Knowles, W. S.; Angew. Chem., Int. Ed. 2002, 41, 1998; Noyori, R.; Angew. Chem., Int. Ed. 2002, 41, 2008; Sharpless, K. B.; Angew. Chem., Int. Ed. 2002, 41, 2024.

118. Hamilton, G. L.; Kang, E. J.; Mba, M.; Toste, F. D.; Science 2007, 317, 496.

119. Nicewicz, D.; MacMillan, D. W. C.; Science 2008, 322, 77.

120. Teller, H.; Flügge, S.; Goddard, R.; Fürstner, A.; Angew. Chem., Int. Ed. 2010, 49, 1949. See also: Teller, H.; Corbet, M.; Mantilli, L.; Gopakumar, G.; Goddard, R.; Thiel, W.; Fürstner, A.; J. Am. Chem. Soc. 2012, 134, 15331.

121. Ranganath, K. V. S.; Kloesges, J.; Schäfer, A. H.; Glorius, F.; Angew. Chem., Int. Ed. 2010, 49, 7786.

122. Ye, B.; Cramer, N.; Science 2012, 338, 504.

123. Mo, F.; Dong, G.; Science 2014, 345, 68.

124. Huo, H.; Shen, X.; Wang, C.; Zhang, L.; Röse, P.; Chen, L.-A.; Harms, K.; Marsch, M.; Hilt, G.; Meggers, E.; Nature 2014, 515, 100.

125. For reviews, see: Huisguen, R.; Angew. Chem., Int. Ed. 1963, 2, 565; Huisguen, R.; Angew. Chem., Int. Ed. 1963, 2, 633.

126. Tornøe, C. W.; Christensen, C.; Meldal, M.; J. Org. Chem. 2002, 67, 3057.

127. Rostovtsev, V. V.; Green, L. G.; Fokin, V. V.; Sharpless, K. B.; Angew. Chem., Int. Ed. 2002, 41, 2596. See also: Himo, F.; Lovell, T.; Hilgraf, R.; Rostovtsev, V. V.; Noodleman, L.; Sharpless, K. B.; Fokin, V. V.; J. Am. Chem. Soc. 2005, 127, 210.

128. Kolb, H. C.; Finn, M. G.; Sharpless, K. B.; Angew. Chem., Int. Ed. 2001, 40, 2004; Moses, J. E.; Moorhouse, A. D.; Chem. Soc. Rev. 2007, 36, 1249; Meldal, M.; Tornøe, C. W.; Chem. Rev. 2008, 108, 2952.

129. Krasovskiy, A.; Knochel, P.; Angew. Chem., Int. Ed. 2004, 43, 3333.

130. For reviews, see: Bao, R. L.-Y.; Zhao, R.; Shi, L.; Chem. Commun. 2015 , 51, 6884; Ziegler, D. S.; Wei, B.; Knochel, P.; Chem. - Eur. J. 2019, 21, 2695.

131. Klaus, S.; Neumann, H.; Zapf, A.; Strübing, D.; Hübner, S.; Almena, J.; Riermeier, T.; Gross, P.; Sarich, M.; Krahnert, W.-R.; Rossen, K.; Beller, M.; Angew. Chem., Int. Ed. 2006, 45, 154.

132. Heppekausen, J.; Stade, R.; Goddard, R.; Fürstner, A.; J. Am. Chem. Soc. 2010, $132,11045$.

133. Tellis, J. C.; Primer, D. N.; Molander, G. A.; Science 2014, 345, 433.

134.Zuo, Z.; Ahneman, D. T.; Chu, L.; Terrett, J. A.; Doyle, A. G.; MacMillan, D. W. C.; Science 2014, 345, 437.

135. Juliá-Hernández, F.; Moragas, T.; Cornella, J.; Martin, R.; Nature 2017, $545,84$.

136. Wiesenfeldt, M. P.; Nairoukh, Z.; Li, W.; Glorius, F.; Science 2017, 357, 908.

137. Edwards, J. T.; Merchant, R. R.; McClymont, K. S.; Knouse, K. W.; Qin, T.; Malins, L. R.; Vokits, B.; Shaw, S. A.; Bao, D.-H.; Wei, F.-L.; Zhou, T.; Eastgate, M. D.; Baran, P. S.; Nature 2017, 545, 213.

138. Kawamata, Y.; Vantourout, J. C.; Hickey, D. P.; Bai, P.; Chen, L.; Hou, Q.; Qiao, W.; Barman, K.; Edwards, M. A.; Garrido-Castro, A. F.; deGruyter, J. N.; Nakamura, H.; Knouse, K.; Qin, C.; Clay, K. J.; Bao, D.; Li, C.; Starr, J. T.; Garcia-Irizarry, C.; Sach, N.; White, H. S.; Neurock, M.; Minteer, S. D.; Baran, P. S.; J. Am. Chem. Soc. 2019, 141, 6392.

139. https://goldbook.iupac.org/html/P/P04580.html, accessed in April 2020.

140. See for instance: Ciamician, G.; Science 1912, 36, 385.

141. Ferraudi, G. J.; Elements of Inorganic Photochemistry, $1^{\text {st }}$ ed.; Wiley: New York, 1988, ch. 3.

142. Gust, D.; Moore, T. A.; Science 1989, 244, 35; Meyer, T. J.; Acc. Chem. Res. 1989, 22, 163; Gust, D.; Moore, T. A.; Moore, A. L.; Acc. Chem. Res. 1993, 26, 198; Balzani, V.; Credi, A.; Venturi, M.; ChemSusChem 2008, $1,26$. 
143. Narayanam, J. M. R.; Stephenson, C. R. J.; Chem. Soc. Rev. 2011, 40 , 102.

144. Koike, T.; Akita, M.; Inorg. Chem. Front. 2014, 1, 562.

145. See for instance: Strieth-Kaltoff, F.; James, M. J.; Teders, M.; Pitzer, L.; Glorius, F.; Chem. Soc. Rev. 2018, 47, 7190.

146. Prier, C. K.; Rankic, D. A.; MacMillan, D. W. C.; Chem. Rev. 2013, 113, 5322. See also: Almeida, A. M.; Almeida, M. V.; Amarante, G. W.; Quim. Nova 2015, 8, 1080.

147. See for instance: Hockin, B. M.; Li, C.; Robertson, N.; Zysman-Colman, E.; Catal. Sci. Technol. 2019, 9, 889.

148. Romero, N. A.; Nicewicz, D. A.; Chem. Rev. 2016, 116, 10075.

149. Roth, H. G.; Romero, N. A.; Nicewicz, D. A.; Synlett 2016, $27,714$.

150. Andrieux, C. P.; Pinson, J.; J. Am. Chem. Soc. 2003, 125, 14801.

151. Reckenthaler, M.; Griesbeck, A. G.; Adv. Synth. Catal. 2013, 355, 2727.

152. Tamayo, A. B.; Alleyne, B. D.; Djurovich, P. I.; Lamansky, S.; Tsyba, I.; Ho, N. N.; Bau, R.; Thompson, M. E.; J. Am. Chem. Soc. 2003, 125, 7377.

153. Tucker, J. W.; Stephenson, C. R. J.; J. Org. Chem. 2012, 77, 1617.

154. Hedstrand, D. M.; Kruizinga, W. M.; Kellogg, R. M.; Tetrahedron Lett. 1978, 19, 1255; van Bergen, T. J.; Hedstrand, D. M.; Kruizinga, W. H.; Kellogg, R. M.; J. Org. Chem. 1979, 44, 4953.

155. Hironaka, K.; Fukuzumi, S.; Tanaka, T.; J. Chem. Soc., Perkin Trans. 2 1984, 1705; Fukuzumi, S.; Koumitsu, S.; Hironaka, K.; Tanaka, T.; J. Am. Chem. Soc. 1987, 109, 305; Fukuzumi, S.; Mochizuki, S.; Tanaka, T.; J. Phys. Chem. 1990, 94, 722.

156. Pac, C.; Ihama, M.; Yasuda, M.; Miyauchi, Y.; Sakurai, H.; J. Am. Chem. Soc. 1981, 103, 6495; Pac, C.; Miyauchi, Y.; Ishitani, O.; Ihama, M.; Yasuda, M.; Sakurai, H.; J. Org. Chem. 1984, 49, 26; Ishitani, O.; Ihama, M.; Miyauchi, Y.; Pac, C.; J. Chem. Soc., Perkin Trans. 1 1985, 1527; Ishitani, O.; Pac, C.; Sakurai, H.; J. Org. Chem. 1983, 48, 2941; Ishitani, O.; Yanagida, S.; Takamuku, S.; Pac, C.; J. Org. Chem. 1987, 52, 2790.

157. Cano-Yelo, H.; Deronzier, A.; Tetrahedron Lett. 1984, 25, 5517.

158. Cano-Yelo, H.; Deronzier, A.; J. Chem. Soc., Perkin Trans. 2 1984, 1093; Cano-Yelo, H.; Deronzier, A.; J. Photochem. 1987, 37, 315.

159. Okada, K.; Okamoto, K.; Morita, N.; Okubo, K.; Oda, M.; J. Am. Chem. Soc. 1991, 113, 9401.

160. Okada, K.; Okamoto, K.; Oda, M.; J. Chem. Soc., Chem. Commun. 1989, 1636.

161. Okada, K.; Okubo, K.; Morita, N.; Oda, M.; Chem. Lett. 1993, 22, 2021.

162. Okada, K.; Okubo, K.; Morita, N.; Oda, M.; Tetrahedron Lett. 1992, 33, 7377.

163. For a recent review on this theme, see: Murarka, S.; Adv. Synth. Catal. 2018, 360, 1735

164. Research performed in the Web of Science using the term "photoredox catalysis" in $29^{\text {th }}$ November 2019.

165. Twilton, J.; Le, C.; Zhang, P.; Shaw, M. H.; Evans, R. W.; MacMillan, D. W. C.; Nat. Rev. Chem. 2017, 1, 0052.

166. Osawa, M.; Nagai, H.; Akita, M.; Dalton Trans. 2007, 8, 827.

167. Kalyani, D.; McMurtrey, K. B.; Neufeldt, S. R.; Sanford, M. S.; J. Am. Chem. Soc. 2011, 133, 18566.

168. Kalyani, D.; Deprez, N. R.; Desai, L. V.; Sanford, M. S.; J. Am. Chem. Soc. 2005, 127, 7330; Deprez, N. R.; Sanford, M. S.; J. Am. Chem. Soc. 2009, 131, 11234; Yu, W.-Y.; Sit, W.; Zhou, Z.; Chan, A. S. C.; Org. Lett. 2009, 11, 3174 .

169. Zoller, J.; Fabry, D. C.; Ronge, M. A.; Rueping, M.; Angew. Chem., Int. Ed. 2014, 53, 13264

170. Zhou, C.; Li, P.; Zhu, X.; Wang, L.; Org. Lett. 2015, 17, 6198.

171. Lang, S. B.; O’Nele, K. M.; Tunge, J. A.; J. Am. Chem. Soc. 2014, 136, 13606.

172. Purser, F.; Moore, P. R.; Swallow, S.; Gouverneur, V.; Chem. Soc. Rev. 2008, 37, 320 .

173. Ye, Y.; Sanford, M. S.; J. Am. Chem. Soc. 2012, 134, 9034.
174. Yoo, W.-J.; Tsukamoto, T.; Kobayashi, S.; Angew. Chem., Int. Ed. 2015, $54,6587$.

175. For a thermal version of this cross-coupling reaction, see: Antilla, J. C.; Buchwald, S. L.; Org. Lett. 2011, 3, 2077.

176. Kautzky, J. A.; Wang, T.; Evans, R. W.; MacMillan, D. W. C.; J. Am. Chem. Soc. 2018, 140, 6522 .

177. Tasker, S. Z.; Standley, E. A.; Jamison, T. F.; Nature 2014, 509, 299; Hu, X.; Chem. Sci. 2011, 2, 1867. See also: Pinheiro, D. L. J.; Amarante, G. W.; Quim. Nova 2018, 41, 1033.

178. Tellis, J. C.; Primer, D. N.; Molander, G. A.; Science 2014, 345, 433.

179. Zuo, Z.; Ahneman, D. T.; Chu, L.; Terrett, J. A.; Doyle, A. G.; MacMillan, D. W. C.; Science 2014, 345, 437.

180. Zuo, Z.; Cong, H.; Li, W.; Choi, J.; Fu, G. C.; MacMillan, D. W. C.; J. Am. Chem. Soc. 2016, 138, 1832.

181. Noble, A.; McCarver, S. J.; MacMillan, D. W. C.; J. Am. Chem. Soc. 2015, 137, 624.

182. Johnston, C. P.; Smith, R. T.; Allmendinger, S.; MacMillan, D. W. C.; Nature 2016, 536, 322.

183. Zhang, P.; Le, C. C.; MacMillan, D. W. C.; J. Am. Chem. Soc. 2016, 138, 8084.

184. Zhang, X.; MacMillan, D. W. C.; J. Am. Chem. Soc. 2017, 139, 11353.

185. Tasker, S. Z.; Jamison, T. F.; J. Am. Chem. Soc. 2015, 137, 9531.

186. Oderinde, M. S.; Jones, N. H.; Juneau, A.; Frenette, M.; Alquila, B.; Tentarelli, S.; Robbins, D. W.; Johannes, J. W.; Angew. Chem., Int. Ed. 2016, 55, 13219.

187. Corcoran, E. B.; Pirnot, M. T.; Lin, S.; Dreher, S. D.; DiRocco, D. A.; Davies, I. W.; Buchwald, S. L.; MacMillan, D. W. C.; Science 2016, 353, 279.

188. Remeur, C.; Kelly, C. B.; Patel, N. R.; Molander, G. A.; ACS Catal. 2017, 7, 6065 .

189. Terrett, J. A.; Cuthbertson, J. D.; Shurtleff, V. W.; MacMillan, D. W. C.; Nature 2015, 524, 330.

190. Oderinde, M. S.; Frenette, M.; Robbins, D. W.; Aquila, B.; Johannes, J. M.; J. Am. Chem. Soc. 2016, 138, 1760.

191. Jouffroy, M.; Kelly, C. B.; Molander, G. A.; Org. Lett. 2016, 18, 876.

192. Cabrera-Afonso, M. J.; Lu, Z.-P.; Kelly, C. B.; Lang, S. B.; Dykstra, R.; Gutierrez, O.; Molander, G. A.; Chem. Sci. 2018, 9, 3186.

193. Yue, H.; Zhu, C.; Rueping, M.; Angew. Chem., Int. Ed. 2017, 57, 1371.

194. Lui, N.-W.; Hofman, K.; Herbert, A.; Manolikakes, G.; Org. Lett. 2018, 20,760.

195. Vara, B. A.; Li, X.; Berritt, S.; Walters, C. R.; Petersson, E. J.; Molander, G. A.; Chem. Sci. 2018, 9, 336.

196. Till, N. A.; Smith, R. T.; MacMillan, D. W. C.; J. Am. Chem. Soc. 2018 , 140,5701

197. Joost, M.; Zeineddine, A.; Estévez, L.; Ladeira, S. M.; Miqueu, K.; Amgoune, A.; Bourissou, D.; J. Am. Chem. Soc. 2014, 136, 14654; Joost, M.; Estévez, L.; Miqueu, K.; Amgoune, A.; Bourissou, D.; Angew. Chem. Int. Ed. 2015, 54, 5236; Wu, C.-Y.; Horibe, T.; Jacobsen, C. B.; Toste, F. D.; Nature 2015, 517, 449.

198. See for instance: Akram, M. O.; Banerjee, S.; Saswade, S. S.; Bedi, V.; Patil, N. T.; Chem. Commun. 2018, 54, 11069; Nijamudheen, A.; Datta, A.; Chem. - Eur. J. 2020, 26, 1442.

199. Sahoo, B.; Hopkinson, M. N.; Glorius, F.; J. Am. Chem. Soc. 2013, 135, 5505.

200. See for instance: Zhang, G.; Peng, Y.; Cui, L.; Zhang, L.; Angew. Chem., Int. Ed. 2009, 48, 3112; Kar, A.; Mangu, N.; Kaiser, H. M.; Beller, M.; Tse, M. K.; Chem. Commun. 2008, 386; Melhado, A. D.; Brenzovich Jr., W. E.; Lackner, A. D.; Toste, F. D.; J. Am. Chem. Soc. 2010, 132, 8885; de Haro, T.; Nevado, C.; Angew. Chem., Int. Ed. 2011, 50, 906.

201. Tlahuext-Aca, A.; Hopkinson, M. N.; Sahoo, B.; Glorius, F.; Chem. Sci. 2016, 7, 89 .

202. Kim, S.; Rojas-Martin, J.; Toste, F. D.; Chem. Sci. 2016, 7, 85.

203. He, Y.; Wu, H.; Toste, F. D.; Chem. Sci. 2015, 6, 1194. 
204. Shu, X.-z.; Zhang, M.; He, Y.; Frei, H.; Toste, F. D.; J. Am. Chem. Soc. 2014, 136, 5844.

205. Tlahuext-Aca, A.; Hopkinson, M. N.; GarzaSanchez, R. A.; Glorius, F.; Chem. - Eur. J. 2016, 22, 5909.

206. Zhang, G.; Liu, Yi, H.; Meng, Q.; Bian, C.; Chen, H.; Jian J.-X.; Wu, L.-Z.; Lei, A.; J. Am. Chem. Soc. 2015, 137, 9273; Wu, C.-J.; Meng, Q. W.; Lei, T.; Zhong, J.-J.; Liu, W.-Q.; Zhao, L.-M.; Li, Z.-J.; Chen, B.; Tung, C.-H.; Wu, L.-Z.; ACS Catal. 2016, 6, 4635; Yi, H.; Niu, L.; Song, C.; Li, Y.; Dou, B.; Singh, A.; Lei, A.; Angew. Chem., Int. Ed. 2017, 56,
1120; Zhang, G.; Hu, X.; Chiang, C.-W.; Yi, H.; Pei, P.; Singh, A. K.; Lei, A.; J. Am. Chem. Soc. 2016, 138, 12037; He, K.-H.; Tang, F.-F.; Zhou, C.-Z.; Zhou, G.-J.; Yang, X.-L.; Li, Y.; Angew. Chem., Int. Ed. 2017, 56, 3080

207. Fabry, D. C.; Ronge, M. A.; Zoller, J.; Rueping, M.; Angew. Chem., Int. Ed. 2015, 54, 2801.

208. Fabry, D. C.; Zoller, J.; Raja, S.; Rueping, M.; Angew. Chem., Int. Ed. 2014, 53, 10228. 